\title{
Differences in persistence between dogs and wolves in an unsolvable task in the absence of humans
}

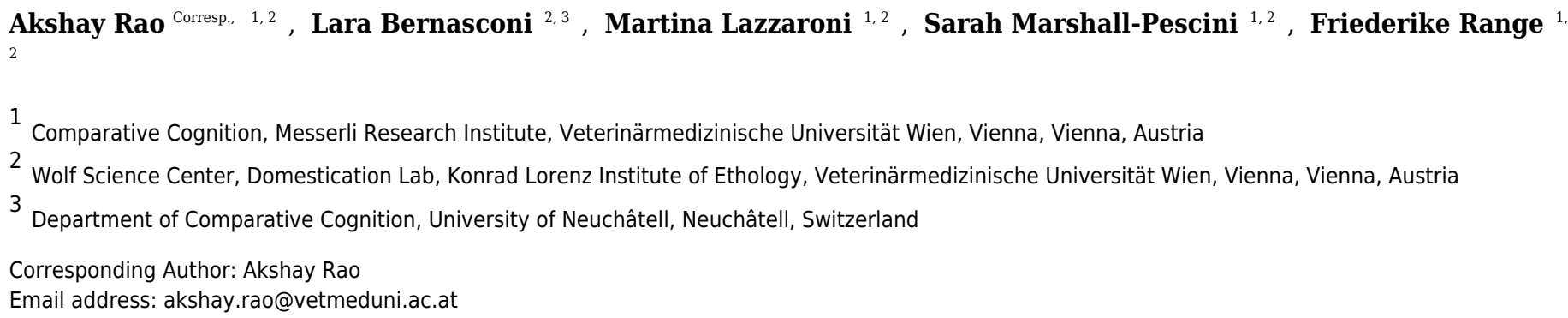

Despite being closely related, dogs consistently perform worse than wolves in independent problem-solving tasks. These differences in problem-solving performance have been attributed to dogs' greater reliance on humans, who are usually present when problemsolving tasks are presented. However, more fundamental motivational factors or behavioural traits such as persistence, behavioural variety and neophobia may also be responsible for differences in task performance. Hence, to better understand what drives dogs' and wolves' different problem-solving performance, it is essential to test them in the absence of humans. Here, we tested equally raised and kept dogs and wolves with two unsolvable tasks, a commonly used paradigm to study problem-solving behaviour in these species. Differently from previous studies, we ensured no humans were present in the testing situation. We also ensured that the task was unsolvable from the start which eliminated the possibility that specific manipulative behaviours was reinforced. This allowed us to measure both persistence and behavioural flexibility more accurately. In line with previous studies, we found wolves to be more persistent than dogs. We also found behavioural variety to be linked to persistence and persistence to be linked to contact latency. Finally, subjects were consistent in their performance between the two tasks. These results suggest that fundamental differences in motivation to interact with objects drive the performance of wolves and dogs in problem solving tasks. Since correlates of problem-solving success i.e. persistence, neophobia, and behavioural variety are influenced by species' ecology, our results support the social ecology hypothesis which postulates that the different ecological niches of the two subspecies (dogs have evolved to primarily be scavengers and thrive on and around human refuse, while wolves have evolved to primarily be group hunters and have a low hunting success rate) at least partly shaped their behaviours. 


\section{Differences in persistence between dogs and wolves in an unsolvable task in the absence of humans.}

\section{Akshay Rao ${ }^{1,2^{*}}$, Lara Bernasconi ${ }^{2,3+}$, Martina Lazzaroni ${ }^{1,2}$, Sarah Marshall-Pescini ${ }^{1,2}$,} 2 Friederike Range ${ }^{1,2}$

$4{ }^{1}$ Wolf Science Center, Domestication Lab, Konrad Lorenz Institute of Ethology, University of 5 Veterinary Medicine, Vienna, Savoyenstraße 1a, A-1160 Vienna

$7{ }^{2}$ Comparative Cognition, Messerli Research Institute, University of Veterinary Medicine,

8 Vienna, Medical University of Vienna, University of Vienna, Vienna Austria

${ }^{3}$ Department of Comparative Cognition, University of Neuchâtel, Neuchâtel, Switzerland.

12 Correspondence:

13 Akshay Rao

14 akshay.rao@vetmeduni.ac.at

15

$16+$ These authors contributed equally to this research 


\section{Abstract}

18 Despite being closely related, dogs consistently perform worse than wolves in independent problem-solving tasks. These differences in problem-solving performance have been attributed to dogs' greater reliance on humans, who are usually present when problem-solving tasks are presented. However, more fundamental motivational factors or behavioural traits such as persistence, motor diversity and neophobia may also be responsible for differences in task performance. Hence, to better understand what drives dogs' and wolves' different problemsolving performance, it is essential to test them in the absence of humans. Here, we tested equally raised and kept dogs and wolves with two unsolvable tasks, a commonly used paradigm to study problem-solving behaviour in these species. Differently from previous studies, we ensured no humans were present in the testing situation. We also ensured that the task was unsolvable from the start, which eliminated the possibility that specific manipulative behaviours were reinforced. This allowed us to measure both persistence and motor diversity more accurately. In line with previous studies, we found wolves to be more persistent than dogs. We also found motor diversity to be linked to persistence and persistence to be linked to contact latency. Finally, subjects were consistent in their performance between the two tasks. These results suggest that fundamental differences in motivation to interact with objects drive the performance of wolves and dogs in problem solving tasks. Because correlates of problemsolving success i.e. persistence, neophobia, and motor diversity are influenced by species' ecology, our results support the social ecology hypothesis that postulates that the different ecological niches of the two subspecies (dogs have evolved to primarily be scavengers and thrive on and around human refuse, while wolves have evolved to primarily be group hunters and have a low hunting success rate) at least partly shaped their behaviours.

\section{Introduction}

Animals need to solve various ecological and social problems to survive. Studies across taxa have found problem-solving success to depend on several psychological propensities (also referred to as the "correlates of problem-solving success"). These include neophobia (the fear of new situations or objects), motor diversity and flexibility (the repertoire of problem-solving behaviours an animal displays, and its ability to find novel solutions to already known problems, or use known solutions to solve novel problems) and, most importantly, persistence (Lefebvre, Reader \& Sol, 2004; Biondi, Bó \& Vassallo, 2010; Hiestand, 2011; Cole, Cram \& Quinn, 2011; Morand-Ferron et al., 2011; Thornton \& Samson, 2012; Benson-Amram \& Holekamp, 2012; Griffin \& Guez, 2014; Moretti et al., 2015; Griffin \& Diquelou, 2015; Huebner \& Fichtel, 2015; Udell, 2015; Borrego \& Gaines, 2016) (defined as task directed motivation and quantified as the amount of time an animal spends tackling a task). These correlates are interconnected, with behavioural flexibility being positively correlated with persistence (Morand-Ferron et al., 2011; Benson-Amram \& Holekamp, 2012; Griffin \& Guez, 2014; Huebner \& Fichtel, 2015; Borrego \& Gaines, 2016) and both being negatively correlated with neophobia (Bouchard, Goodyer \& 
Lefebvre, 2007; Biondi, Bó \& Vassallo, 2010; Thornton \& Samson, 2012; Sol, Griffin \& Bartomeus, 2012; Benson-Amram \& Holekamp, 2012; Griffin \& Guez, 2014; Moretti et al., 2015; Borrego \& Gaines, 2016). They are influenced by a species' ecology, social structure and living conditions (Webster \& Lefebvre, 2001; Lefebvre, Reader \& Sol, 2004; Cauchard et al., 2013; Griffin, Diquelou \& Perea, 2014). For example, birds in variable environments and habitats were found to be less neophobic and have greater motor diversity and flexibility than conspecifics in more stable environments (Mettke-Hofmann, Winkler \& Leisler, 2002; Sol, Lefebvre \& Rodriguez-Teijeiro, 2005; Sol et al., 2011; Kozlovsky, Branch \& Pravosudov, 2015). Persistence was higher in social carnivores than in closely related non-social ones, as well as in captive hyenas than in wild conspecifics (Benson-Amram, Weldele \& Holekamp, 2013; Borrego \& Gaines, 2016). Personality (or behavioural type), has also been shown to play a role in problem solving styles (Sih \& Del Giudice, 2012). For instance, in certain contexts, a reactive behavioural type is associated with slower, less exploratory behaviour and less persistence, while a proactive behavioural type, with faster exploratory behaviour and higher persistence (Sih \& Del Giudice, 2012). Performing multiple problem-solving experiments over time can help understand consistency in animals' performance and hence, the effect behavioural types have on the correlates of problem-solving success.

Dogs and their closest living ancestors, wolves (Frantz et al., 2016) differ strongly in their problem solving success in various paradigms (Frank \& Frank, 1982; Frank et al., 1989; Miklósi et al., 2003; Udell, Dorey \& Wynne, 2008; Hiestand, 2011; Range \& Virányi, 2014; MarshallPescini, Virányi \& Range, 2015; Udell, 2015; Heberlein et al., 2016; Rao et al., 2017; Brubaker et al., 2017; Marshall-Pescini et al., 2017a,b). For instance, wolves were more task-focussed, showed more motor diversity, were more persistent and were able to generalise better than dogs in a string-pulling task (Hiestand, 2011). They were faster and more successful at obtaining food from puzzle boxes (Frank \& Frank, 1982; Udell, 2015; Rao et al., 2017; Brubaker et al., 2017) and performed better at a visual discrimination task than dogs (Frank et al., 1989). These differences have partly been attributed to the different ecological niches they live in (Virányi et al., 2008; Range \& Virányi, 2013, 2014; Marshall-Pescini, Virányi \& Range, 2015; Werhahn et al., 2016; Marshall-Pescini et al., 2017c,a; Brubaker et al., 2017). Unlike wolves, dogs live in a human dominated niche (Marshall-Pescini et al., 2017a). They may hence rely on humans more than wolves do, both, in terms of social support (Gácsi et al., 2005), and possibly as 'problemsolvers'. Authors often describe dogs displaying copious amounts of human directed behaviours during problem-solving experiments. There is ample evidence that when confronted with a problem in the presence of a human, dogs are more likely than wolves to look towards and/or interact with the human instead of engaging in the task (Miklósi et al., 2003; Udell, 2015; Brubaker et al., 2017).

Two hypotheses might explain why dogs engage and persist less than wolves in these situations. First, it is possible that previous experience with humans, who often solve problems for dogs, drives the dogs' behaviour. In the human-dominated niche that dogs live in, humans often 
94 provide support in all important domains including providing access to resources such as food 95 (Marshall-Pescini et al., 2017a). Hence, dogs might expect humans to solve problems for them 96 and thus turn to humans for help without trying very hard to solve problems by themselves.

97 However, differences in problem-solving success are visible even in dogs and wolves that have 98 identical experience with humans (Gácsi et al., 2009; Virányi \& Range, 2011; Range \& Virányi, 99 2014; Marshall-Pescini, Virányi \& Range, 2015; Marshall-Pescini et al., 2016, 2017c; Heberlein 100 et al., 2016; Rao et al., 2017). The second, likelier hypothesis that may explain differences in 101 dogs' and wolves' problem-solving performance, is that adaptations to their respective feeding 102 ecologies (Fleming et al., 2017) have resulted in dogs and wolves evolving differences in their 103 correlates of problem-solving success, particularly in persistence. Wolves are primarily hunters 104 (Fleming et al., 2017) with low success rates (between 10\% and 49\%) and need to be highly 105 persistent to survive (Mech, Smith \& MacNulty, 2015). Dogs, however, are primarily scavengers 106 (Marshall-Pescini et al., 2017a; Fleming et al., 2017), dependant mostly on human refuse 107 (Atickem, Bekele \& Williams, 2009; Vanak \& Gomper, 2009; Newsome et al., 2014; Marshall108 Pescini et al., 2017a; Fleming et al., 2017) and may not need to be as persistent. Accordingly, in 109 a problem-solving experiment with a human present, dogs might be less persistent, give up 110 earlier than wolves, and then, as there is nothing else to do, explore the test environment, do 111 nothing or turn towards the human. Following this reasoning, turning to humans might not be a 112 strategic choice to obtain help or support instead of solving the task independently, as has been 113 suggested previously (Miklósi et al., 2003; Gácsi et al., 2005; Persson et al., 2015; Konno et al., 114 2016) but rather a consequence of reduced persistence (Rao et al., 2017). Overall, while the 115 ecology-based hypothesis postulates fundamental differences in motivation (regardless of human 116 presence), the human reliance hypothesis suggests that, while dogs and wolves might have 117 similar problem-solving skills (when alone), dogs turn towards humans as an alternative strategy 118 to solving problems by themselves.

119 A first step towards teasing these hypotheses apart and better quantifying persistence without 120 direct human influence on dogs' and wolves' performance is to conduct problem-solving tasks in 121 the absence of humans with dogs and wolves whose rearing history and human exposure is 122 controlled for. Udell (2015) headed in this direction by testing subjects in three conditions 123 alone, with a silent human, and with an encouraging human. While wolves were more persistent 124 than pet dogs in the task even when alone suggesting that dogs' may have a "generalized 125 dependence on humans" (Pg. 1), authors also highlight that such dependence may be a result of 126 differences in the life experiences that the pet dogs and hand-reared wolves had. Pet dogs may

127 have been discouraged by their owners to 'problem-solve' the trash-can or kitchen drawers, 128 which may have resulted in dogs being inhibited when confronting a novel object. Differences in 129 life experience are in fact known to affect problem-solving in dogs: highly trained dogs (agility, 130 retriever, search and rescue) showed more independent problem-solving abilities than untrained 131 pet dogs, who conversely looked towards the owner longer (Marshall-Pescini et al., 2008) in 132 such tasks. 
133 Here, we presented similarly raised and kept pack-living dogs and wolves with two different

134 unsolvable tasks in the absence of humans on two separate occasions. Each task consisted of an

135 object baited with food that was inaccessible to the animal. To avoid animals' expectations

136 regarding the role of a human in the task, we presented the object in their home enclosure where

137 humans rarely enter. Humans entering the enclosure is instead associated with a routine

138 enrichment procedure where the animals are shifted out of the home enclosures, humans scatter

139 food in the enclosures, leave and then shift the animals back in. Apart from removing the

140 expectation of human presence, using an enclosure associated with the enrichment procedure

141 (which is familiar to all animals) guaranteed a similar motivational state for all subjects.

142 Furthermore, because food motivation is known to influence problem-solving behaviour (Laland

143 \& Reader, 1999; Sol, Griffin \& Bartomeus, 2012; Griffin, Diquelou \& Perea, 2014; Griffin \&

144 Guez, 2014), we tested subjects early in the morning without feeding them the evening prior to

145 the test. Finally, as food motivation is influenced by food quality (Fontenot et al., 2007; Dufour

146 et al., 2012; Hillemann et al., 2014); we used high value food (based on a previously performed

147 preference test) for testing (Rao, et al. in press).

148 We measured persistence as the time spent manipulating the presented objects. We predicted that

149 if human presence during testing and/or general differences in wolf-dog experiences with

150 humans (Udell, 2015) are the main factors responsible for wolves' greater persistence in

151 problem-solving experiments, dogs and wolves would not differ significantly in their persistence

152 in the current study. If, however, adaptations to the respective feeding niches play a bigger role

153 than their experience with humans, wolves would be significantly more persistent than dogs.

154 Although several studies have compared species (Griffin \& Guez, 2014) and evaluated the effect

155 of different environments on problem solving behaviours, fewer studies have also examined how

156 problem-solving correlates relate to each other (birds: (Griffin \& Guez, 2014), mammals:

157 (Thornton \& Samson, 2012; Benson-Amram \& Holekamp, 2012; Borrego \& Gaines, 2016)).

158 Therefore, in the current study, apart from persistence, we also measured motor diversity (the

159 number of different object-directed manipulative behaviours exhibited) when subjects attempted

160 to extract the food from the presented objects, the latency for subjects to contact each object

161 (contact latency; typically used as a measure of neophobia (Griffin \& Guez, 2014)) and the body

162 posture (low-fearful vs. high-confident) exhibited during approach and manipulation.

163 Studies have found animals that spend longer engaged in a task to also tend to utilize a greater

164 variety of behaviours (Griffin, Diquelou \& Perea, 2014; Logan, 2016; Johnson-Ulrich, Johnson-

165 Ulrich \& Holekamp, 2018). In line with this, we expected to find a positive correlation between

166 persistence and motor diversity. The relationship between persistence and contact latency may

167 be more multifaceted, as contact latency could be a measure of neophobia but also a measure of

168 (dis)interest in an object. To try teasing these possibilities apart, we included body postures when

169 analysing the data for contact latency. If contact latency was a measure of neophobia, we

170 expected it to be higher in subjects that show an insecure body posture (known to be related to 
171 fear and insecurity (Marshall-Pescini et al., 2017c)) during approach. If no such relationship

172 emerged, it may be that contact latency was a measure of the animal's interest in the task.

173 Sih \& Del Giudice, (2012) proposed that persistence, neophobia and interest may form parts of a

174 behavioural syndrome. If these are indeed personality traits, they would be correlated with each

175 other and be stable over time and context (Réale et al., 2007). Hence, independently of whether

176 contact latency is a measure of neophobia or interest, we expected it to be negatively correlated

177 with persistence in both species. Finally, we evaluated whether individual consistency in

178 persistence and in contact latency would emerge across the two tasks. Considering studies

179 suggesting that these may indeed be personality traits (Sih \& Del Giudice, 2012; Johnson-Ulrich,

180 Johnson-Ulrich \& Holekamp, 2018), we predicted that our subjects would indeed be consistent

181 in their persistence and contact latency across tasks.

182 To sum up, our study had three aims: (1) to test hypotheses about why dogs and wolves (with

183 controlled rearing history and human exposure) differ in their persistence, (2) to assess

184 relationships between the correlates of problem-solving success and (3) test subjects' consistency

185 in performance across tasks.

\section{$1863 \quad$ Materials and methods}

\section{$187 \quad 3.1 \quad$ Ethics Statement}

188 Special permission to use animals (wolves) in such cognitive studies is not required in Austria

189 (Tierversuchsgesetz 2012-TVG 2012). The "Tierversuchskommission am Bundesministerium

190 für Wissenschaft und Forschung (Austria)" allows research without special permissions

191 regarding animals. We obtained ethical approval for this study from the 'Ethik und

192 Tierschutzcommission' of the University of Veterinary Medicine (Protocol number ETK-

193 07/08/2016).

\section{$194 \quad 3.2$ Subjects}

195 We tested 17 adult mixed-breed $\operatorname{dogs}(7 \mathrm{~F}, 10 \mathrm{M}$; mean age $+\mathrm{SD}=4+1.6$ years) (Canis lupus

196 familiaris) and 12 adult Grey wolves ( 4 F, $8 \mathrm{M}$; mean age $+\mathrm{SD}=6.3+1.7$ years) (Canis lupus)

197 similarly raised and kept in conspecific packs at the Wolf Science Centre, Austria, from October

1982016 to February 2017 (Table 1).were hand-raised with conspecifics in peer groups by humans

199 (dogs were raised separately from wolves, both at different times). The animals had continuous

200 access to humans who bottle-fed and later hand-fed them in the first 5 months of their life.

201 During the first weeks of puppyhood, the animals were kept inside. They had free access to a

$2021,000 \mathrm{~m}^{2}$ outdoor, "puppy" enclosure from their second month on and were moved to 2,000 -

$2038,000 \mathrm{~m}^{2}$ "living" enclosures at five months of age. The animals, as adults, live in these larger

204 "home enclosures". Packs are regularly moved from one home enclosure to another for logistic 
205

206

207

208

209

210

211

212

213

214

215

216

\section{7}

218

219

220

221

222

223

\section{4}

225

226

227

228

229

230

231

232

233

234

235

236

237

238

239

reasons (such as to make it easier to walk an animal on leash from its home enclosure to a test conducted indoors, or to a touristic event). All packs have resided in all home enclosures.

Every enclosure is equipped with bushes, trees, logs, shelters and permanent drinking water installations. While humans are not continuously present in living enclosures, all animals do have social contact with them through several means: animals voluntarily participate in cognitive and behavioural experiments, and/or training, and/or other social events at least once a day, and hence have social contact with humans. Animals are rewarded with food for participating in these activities. This routine ensures that all animals are cooperative and attentive towards humans and allows weekly veterinary checks without sedating the animals. All animals at the WSC are intact and males are vasectomised. Over the course of their lives, all animals at the WSC have participated in the same behavioural and cognitive experiments and have participated in the same training activities.

\subsection{Apparatus}

One object (henceforth referred to as the "ball") was a perforated, hard plastic sphere $24 \mathrm{~cm}$ in diameter, weighing $1.5 \mathrm{~kg}$ (commercially available "Lion Feeder Ball" from www.ottoenvironmental.com) (Figure 1), the other was a modified, perforated PVC sewage pipe (22 $\mathrm{cm}$ in diameter, $40 \mathrm{~cm}$ in length henceforth referred to as the "pipe") (Figure 2). Prior to the test, each object was baited with large chunks of strongly smelling sausage and meat out of sight of the subject.

\subsection{Experimental Setup}

Before a test session began, we anchored one of the objects using a 30-cm long metal chain to a camping peg driven into the ground in the subjects' home enclosure and marked a two-meter radius around it with a commercially available, bright red timber marking spray. This was done out of sight of the test subject. The peg was positioned such that any interactions the subject had with the object could be recorded from multiple angles without any visual obstructions. Two video cameras (recording at $1920 \times 1080$ pixels at 50 progressive frames per second) and one smartphone (Samsung Galaxy Note 2) were mounted on tripods outside the enclosures at three different angles. We used "IP Webcam", a freely available app developed by Pavel Khlebovich (http://ip-webcam.appspot.com/), to remotely monitor the trial, whilst staying out of sight of the subject during the entire procedure.

Subjects were tested in their home enclosure as they least expect a human to be present inside. Tests are normally conducted in specific "testing enclosures" at the Wolf Science Centre and humans (including trainers) only visit the animals in the home enclosures in very specific contexts (i.e. pack visits, animal care and short, training demonstrations during public guided tours). Subjects were in different home enclosures when they were tested with each object. 


\subsection{Procedure}

241 We tested subjects individually between 7:00 and 10:00 a.m. One animal per pack was tested per

242 session and two to three sessions were conducted per week, never on consecutive days. To

243 ensure high food motivation, the subjects were not fed the evening before the test. Before the

244 test, we shifted the entire pack out of their home enclosure into an empty enclosure from where

245 their home enclosure was out of sight. The test object was placed in the subjects' home enclosure

246 (see "Experimental Setup") after which, the focal subject was led back into the home enclosure.

247 We started the test session when the animal entered the $2 \mathrm{~m}$-radius (see "Start" in Table 2).

248 The subject was given 5 minutes to make first contact with the object. We defined "First

249 Contact" as the first time the subject touched or sniffed the object (in case of a sniff, the nose

250 was within $5 \mathrm{~cm}$ of the object). In case there was no "First Contact" within 5 minutes, the test

251 session was terminated. If the subject did not interact (i.e. "Sniff" or "Manipulate" the object -

252 see Table 2 for definitions of all behaviours and behavioural states) with the apparatus at all for 5

253 minutes after "First Contact", the session was terminated. After the subject started interacting

254 with the object, there was no limit on the duration it could continue to do so. Each time the

255 subject stopped interacting with the object, we started a 5-minute countdown. If the subject

256 resumed interacting with the object before the countdown expired, we let the test session

257 continue and reset the 5-minute counter. If the subject did not resume interacting with the object

258 by the time the countdown expired, we terminated the test session. To simplify, if a subject

259 started interacting with the object, it could continue doing so for an infinite duration and pause as

260 many times as it liked, as long the pauses were under 5 minutes; once it paused for more than 5

261 minutes, the test session ended.

262

263

264

265

266

267

268

269

270

271

272

273

274

275

After the session ended, we shifted the subject out of the home enclosure and retrieved the object. We carefully washed each object after each session to remove any possible odour cues left by the previously tested subject. Each subject was tested first with the ball and re-tested them with the pipe one and a half to three months later. Two wolves, Chitto and Tala, had to be tested with the pipe six months after their test with the ball due to the onset of the mating season. As we needed to keep our study comparable to a complementary study with free ranging and pet dogs which were presented with only the ball (Lazzaroni et al. in prep), we were unable to counterbalance the presentation order of the two objects. We used each object only once per subject to avoid object-specific learning effects (e.g. to avoid subjects learning "food from inside this particular green ball cannot be extracted").

\subsection{Behavioural Coding}

We recorded all tests on video and coded behaviours using Solomon Coder beta 100926 (a behaviour coding software developed by András Péter, Dept. of Ethology, Budapest, www.solomoncoder.com). We categorised manipulative behaviours based on the number of 
276 body parts involved and the nature of the behaviour. For instance, we differentiated between

277 using paws to hold an object and to scratch vigorously at the object while the subject

278 simultaneously gnawed at it. "Holding" an object with the paws added stability which probably

279 made "Biting" more efficient, while "Scratching" did not add stability, but was probably a

280 different strategy to extract the food within the object. The coded behaviours and their

281 definitions are summarized in Table 2. See the supplementary video for an example of each

282 behaviour. We defined "Persistence" as the time (in seconds) a subject spent in the

283 "Manipulating" behavioural state. We defined "Contact Latency" as the time (in seconds) a

284 subject took from "Start" to "First Contact". We defined "Motor Diversity" as the number of

285 unique "Manipulative Behaviours" shown by a subject.

\section{$286 \quad 3.7 \quad$ Analyses}

287 We excluded one dog (Gombo) from the analyses for the pipe as he extracted some food from

288 the object due to an apparatus malfunction (a piece of meat that we used had several long fibres

289 that were too close to the holes in the apparatus, which allowed Gombo to easily grab them and

290 pull a piece of meat out through one of the holes). We excluded one wolf (Una) from the latency

291 analyses for the ball as her contact latency was an outlier ( 28 seconds; $G=5.09, \mathrm{U}=0.007, \mathrm{P}<$

292 0.001) (potentially because she was tested at the onset of the breeding season). We excluded one

$293 \mathrm{dog}$ (Nuru) from the analyses of the pipe as he was overly persistent with the pipe, making his

294 manipulation duration an outlier ( 1.361 seconds, $\mathrm{G}=3.10, \mathrm{U}=0.63, \mathrm{P}=0.008)$. We used

295 Grubbs tests (Grubbs, 1950) R version 3.4.3 (R Core Team, 2017) to confirm that these

296 individuals were indeed outliers ("outliers" version 0.14) (Komsta, 2006). See the

297 supplementary material for how results changed when these latter two individuals were included

298 in the analyses. All other subjects were included in the analyses (Ball: $\mathrm{N}=11$ wolves, 17 dogs,

299 Pipe: $\mathrm{N}=12$ wolves, 15 dogs).

300 We used inter-class correlations (Shrout \& Fleiss, 1979) implemented with the "psych" package

301 (version 1.7.8) (Revelle, 2017) in R version 3.4.3 (R Core Team, 2017) to calculate inter-

302 observer reliability. A second coder coded $20 \%$ of the data and all variables achieved reliability

303 coefficients between 0.89 and 0.99 between the two coders.

304 We first used an exploratory, principal component analysis (PCA) for each object to understand

305 our data. Performing several univariate analyses may not have allowed us to understand the

306 combined effect of all explanatory variables on our subjects' task performance. As we were

307 primarily interested in variables that have previously been shown to relate to problem-solving

308 success, we included persistence, motor diversity, latency to contact, approach posture and

309 likelihood of manipulation as explanatory variables. While we could have included several more

310 variables (such as the frequencies of each manipulative behaviour), we chose to restrict the

311 number of explanatory variables due to our relatively small dataset. We used the PCAmixdata

312 package (version 3.1) (Chavent et al., 2014) in R (version 3.5.1) (R Core Team, 2018) which is 
313 designed for analysing multivariate data that is a mixture of continuous, discrete and categorical 314 variables.

315 The PCAmixdata analysis algorithm classified subjects based on our explanatory variables which 316 did not include "Species". The rationale behind leaving species out of the analysis was to allow 317 the algorithm to classify subjects purely based on task performance without any pre-existing 318 bias. This way, if, for example, there were distinct behavioural differences between the two 319 species, it would result in clusters composed entirely of dogs and entirely of wolves, with each 320 cluster having significantly different values of one or more behavioural variables. Conversely, if 321 there were no differences, we may still have found clusters with different variable values, but

322 these clusters would be mixtures of dogs and wolves. We ran a separate multivariate analysis for 323 each object as including data from both objects in one analysis made it difficult to meaningfully 324 interpret the clusters' structures. Separating the two objects allowed us to analyse whether subjects performed similarly with both objects. Additionally, we applied an orthogonal rotation procedure to each PCA to make interpretation easier. We used the "PCArot" function which uses a generalization of the varimax procedure for mixed data (Chavent, Kuentz-Simonet \& Saracco, 2012). This procedure helps associate variables with a selected number of principal components (or dimensions) more clearly by providing either large (almost 1) or small (almost 0 ) loadings. While the variable loadings on each dimension (and hence the variance explained by each dimension) change after rotation, the total variance explained by the selected dimensions remains unchanged.

333 The PCA gave us useful insights into patterns in our data, but did not let us test whether there was a statistically significant difference in dogs' and wolves' performance when interacting with the two objects (we did not make any inferences based on results from the PCA). Hence, we further analysed persistence, motor diversity and contact latency individually using generalised additive models for location, scale and shape ("gamlss" version 5.1-0) (Stasinopoulos \& Rigby, 2007) in R version 3.5.1. We used the "gamlss.Dist" package (version 5.0-6) to fit distributions to our data. We evaluated the distribution of each response variable and specified the best fitting distribution in the models. We evaluated model fits both by their generalised Akaike information criteria (Akaike, 1974) and by the distribution of the model residual quantile-quantile plots. This approach enabled us to analyse the data without major transformations, which could have affected our interpretations of the results (Feng et al., 2014; Lo \& Andrews, 2015).

344 To reduce the risk of our choice of distributions resulting in overfitting models to our data, we validated our models' results by fitting identical models with other probable distributions and 346 compared models with different distributions but similar AIC values. Further, when our data fit multi-parametric variations of the same distribution equally well, we used the distribution with

348 fewer parameters (e.g. "Persistence" fit Weibull-1, Weibull-2 and Weibull-3 but we used

349 Weibull-1, as this distribution is described with one parameter as against two or three). Results

350 did not change between models, implying that they were robust against choice of distribution. 
351 For the sake of brevity, we have only reported results from models with the best fitting

352 distributions here. Please see the supplementary material for the complete distribution selection,

353 model reduction and model validation processes, outputs and scripts. To account for repeated

354 measures, we included the individual as a random factor in all models that included "Object" as a

355 fixed factor. As our subjects ages' varied, we included "Age" as a factor in all our models to

356 account for any effects this may have on subjects' task performance (Siwak, 2001). When

357 interactions were not statistically significant, we ran a reduced model that included the same

358 fixed effects but not the interaction term. We have reported the results from these, reduced

359 models whenever interactions were not significant.

360 Based on the PCA's results, we used a Fisher's Exact Test in R version 3.5.1 to investigate 361 whether dogs and wolves differed statistically in their likelihood to manipulate the objects. Our

362 PCA suggested that wolves and dogs may differ in their persistence, but that this difference may

363 be influenced by object type. To investigate this, we used a GAMLSS model to evaluate the

364 effects of species, object type and a two-way interaction between them, on the response variable

365

366

367

368

369

370

371

372

373

374

375

376

377

378

379

380

381

382

383

384

385

386

387

persistence. To ensure model convergence, we added a miniscule constant (0.00001) to all persistence values. We fit this model with the Gamma distribution and validated it with the BoxCox T Original, Weibull and Log-normal distributions. This process allowed us to achieve our first aim of testing our hypothesis about dog-wolf differences. We left motor diversity out of this analysis for two reasons: (1) our hypothesis pertained specifically to differences in persistence between dogs and wolves and (2) from our PCA (and from further analysis for our second aim), persistence and motor diversity appeared to be correlated; this collinearity may have negatively impacted our interpretation of model results (Graham, 2003).

For our second aim, we focussed on understanding the relationships between the correlates of problem-solving success within dogs and within wolves. We analysed data for both species separately by running separate GAMLSS models for dogs and wolves. The rationale behind this decision was that only hypothesis we had pertaining to dog-wolf differences was about persistence and did not encompass other behavioural measures.

We ran two GAMLSS models with contact latency as the response variable. Our PCA suggested that contact latency may be related to object type, and that approach posture and persistence may influence contact latency differently in both objects. Hence, for dogs, we included object type, persistence, approach posture and two two-way interactions (object type by persistence and object type by approach posture) as explanatory variables. For dogs, we fit the model with the Inverse Gaussian distribution and validated it with the Inverse Gamma, Log-normal and Gamma distributions. For wolves, we fit the model with the Log-normal distribution and validated it with the Gamma, Weibull and Box-Cox Cole-Green distributions.

We ran two GAMLSS models with motor diversity as response variable. As the PCA suggested that persistence and motor diversity may be correlated, and because this correlation appeared 
388 slightly different between the two objects, we included persistence, object type and a two-way

389 interaction between persistence and object type as explanatory variables. For dogs, we fit the

390 model with the Zero Adjusted Poisson distribution and validated it with the Zero Inflated

391 Poisson, Zero Adjusted Negative Binomial (Type I) and Zero Inflated Negative Binomial (Type

392 I) distributions. For wolves, we fit the model with the Poisson distribution and validated it with

393 the Zero Adjusted Poisson, Negative Binomial type I and Generalised Poisson Distributions.

394 Our last aim was to test subjects' consistency in performance between the two tasks. As we had 395 not restricted the duration a subject could manipulate both objects and as contact latency could

396 have varied due to the layout of the enclosure subjects were tested in, absolute persistence and

397 latency values may not have been meaningfully comparable. Hence, we scaled these values from

3980 to 1 in each task separately using the following formula for both variables: $V_{s}=$

$399 \frac{V_{i}-\operatorname{Min}\left(V_{\text {all }}\right)}{\operatorname{Max}\left(V_{\text {all }}\right)-\operatorname{Min}\left(V_{\text {all }}\right)}$ where $\mathrm{V}_{\mathrm{s}}=$ scaled value (persistence or contact latency), $\mathrm{V}_{\mathrm{i}}=$ individual's

400 unscaled value, Min / Max $\left(\mathrm{V}_{\text {all }}\right)=$ the minimum / maximum values for that object. We used a

401 Spearman's rank correlation on the scaled persistence and scaled contact latency data to test

402 whether subjects were consistent in their persistence and contact latency between the two

403 objects. We calculated a consistency score for persistence and contact latency by taking the

404 absolute value of the difference between subjects' scaled persistence scores (or scaled contract

405 latency scores) for the ball and for the pipe. We used separate GAMLSS models to assess the

406 effect of species on the consistency scores for persistence and contact latency. For persistence,

407 we fit the model with the Generalised Beta Type 1 distribution and validated it with the Logit

408 Normal distribution. For contact latency, we fit the model with the Simplex distribution and

409 validated it with the Logit Normal and Beta Original distributions.

\section{Results}

\section{$411 \quad 4.1 \quad$ Multivariate approach to wolf-dog comparison}

412 The PCA for the ball produced five dimensions, the first three of which explained $83.28 \%$ of the 413 variance in our data. Pre and post orthogonal rotation results are summarised in Table 3 . The

414 rotation significantly improved variable loadings on dimensions 1 and 3. Hence, we investigated

415 these dimensions further. We found that dogs and wolves segregated into two near-distinct

416 clusters along dimension 1, but not along dimension 3 (Figure 3, panel A). Persistence (0.82) and

417 motor diversity (0.85) loaded very strongly on dimension 1 (Figure 3, panel B), suggesting that

418 the segregation between dogs and wolves was likely due to differences in either persistence,

419 motor diversity, or both and that these two variables may be correlated. We found two distinct

420 clusters along dimension 3, but each of these clusters were composed of both dogs and wolves.

421 Approach posture loaded very strongly (0.98) on dimension 3 (as did contact latency, but to an

422 almost negligible extent: 0.009). This suggested that there may be a very weak (if any) 
423 connection between contact latency and approach posture, and that neither of these variables

424 were likely to be responsible for dog-wolf differences.

425 The PCA for the pipe also produced five dimensions, the first three of which explained 87.03\% 426 of the variance in our data. Pre and post orthogonal rotation results are summarised in Table 4.

427 We investigated dimensions 1 and 2 further as the rotation significantly improved variable 428 loadings on them. Unlike with the ball, wolves and dogs did not segregate into distinct clusters along either dimension (Figure 4, panel A).

\subsection{Differences in persistence between wolves and dogs (Model approach)}

Overall, 14 out of 17 dogs manipulated the ball and 10 out of 15 dogs manipulated the pipe. In contrast, all 11 wolves manipulated the ball and all 12 wolves manipulated the pipe. Wolves were significantly more likely to manipulate objects than dogs (Fisher's Exact Test, Odds Ratio $=0.0,95 \%$ conf. interval $0.00-0.71, \mathrm{P}=0.015)$. Though the PCA suggested that persistence may have been affected by object type, the interaction between species and object was not significant, GAMLSS: $\mathrm{t}=-1.47, \mathrm{P}=0.15$ ). Wolves were more persistent than dogs (GAMLSS: $\mathrm{t}$ $=3.73, \mathrm{P}<0.001$ ) in their manipulation of the objects regardless of object-type (Figure 5, panel A). Neither subjects' age (GAMLSS: $\mathrm{t}=0.76, \mathrm{P}=0.45$ ) nor object type (GAMLSS: $\mathrm{t}=1.06, \mathrm{P}=$ 0.29) affected persistence (Figure 5, panel B).

\subsection{Relationship between correlates of problem-solving within wolves and dogs}

Contact latency decreased with persistence in both dogs (GAMLSS: $\mathrm{t}=-4.35, \mathrm{P}<0.001$ ) and wolves (GAMLSS: $\mathrm{t}=-3.42, \mathrm{P}<0.01$ ). Neither the interaction between object type and persistence (GAMLSS; Dogs: $\mathrm{t}=1.91, \mathrm{P}=0.07$, Wolves: $\mathrm{t}=-0.96, \mathrm{P}=0.35$ ) nor that between object type and approach posture significantly affected contact latency (GAMLSS; Dogs: $\mathrm{t}=\mathrm{-}$ 1.32, $\mathrm{P}=0.20$, Wolves: $\mathrm{t}=-1.61, \mathrm{P}=0.13$ ). Neither object type (GAMLSS; Dogs: $\mathrm{t}=1.44, \mathrm{P}=$ 0.16 , Wolves: $\mathrm{t}=-0.96, \mathrm{P}=0.35$ ) nor approach posture (GAMLSS; Dogs: $\mathrm{t}=0.43, \mathrm{P}=0.67$, Wolves: $\mathrm{t}=-1.72, \mathrm{P}=0.10)$ significantly affected contact latency in either species. Contact latency decreased with age in dogs (GAMLSS: $\mathrm{t}=-2.85, \mathrm{P}<0.001$ ) but not in wolves (GAMLSS: $\mathrm{t}=-0.04, \mathrm{P}=0.97$ ).

Motor diversity increased with persistence in both dogs (GAMLSS: $\mathrm{t}=3.74, \mathrm{P}<0.001$ ) and wolves (GAMLSS: $\mathrm{t}=3.72, \mathrm{P}=0.001$ ). The interaction between object type and persistence was not significant (GAMLSS; Dogs: $\mathrm{t}=-1.67, \mathrm{P}=0.11$, Wolves: $\mathrm{t}=1.62, \mathrm{P}=0.12$ ). Neither object type (GAMLSS; Dogs: $\mathrm{t}=-1.74, \mathrm{P}=0.09$, Wolves: $\mathrm{t}=-1.61, \mathrm{P}=0.12$ ) nor age (GAMLSS; Dogs: $\mathrm{t}=-0.58, \mathrm{P}=0.57$, Wolves: $\mathrm{t}=1.20, \mathrm{P}=0.24$ ) significantly affected motor diversity in either species.

\subsection{Individual consistency}


457 Both subjects' persistence (Spearman's $\rho=0.71, \mathrm{P}<0.001$ ) and contact latency (Spearman's $\rho=$ $4580.64, \mathrm{P}<0.001)$ across tasks were significantly correlated. Figure 6 shows individuals' scaled 459 persistence in both tasks. Overall, dogs were significantly more consistent both, in their 460 persistence (GAMLSS: $\mathrm{t}=-2.31, \mathrm{P}=0.031$ ) as well as in their contact latency (GAMLSS: $\mathrm{t}=$ $4612.62, \mathrm{P}=0.02)$ than wolves.

462 For descriptive statistics of both groups' performance in each task and for complete model 463 information, see the supplementary material.

\section{Discussion}

465

466

467

468

469

470

471

472

473

474

475

476

477

478

479

480

481

482

483

484

485

486

487

488

489

490

491

492

We tested similarly raised dogs and wolves with two unsolvable tasks in the absence of humans on two separate occasions with three aims: First, to test hypotheses about why dogs and wolves with controlled rearing history and human exposure differ in their persistence in an independent problem-solving task; second, to evaluate relationships between correlates of problem-solving success in our subjects and third, to assess our subjects' consistency in task performance. We used two approaches when analysing our data: first, a multivariate principal component analysis and second, a set of univariate mixed models.

Results from the multivariate approach showed wolves to be more persistent and have greater motor diversity with the ball than with the pipe. This may have been due to wolves' ability to generalise (Hiestand, 2011). Wolves may have learned that trying to solve a task presented in that specific setting was futile and did not persist as long with the pipe which was presented as the second task. Alternatively, it is possible that a neophobic response may have affected wolves' persistence and motor diversity negatively (Sol et al., 2011; Thornton \& Samson, 2012; Griffin \& Guez, 2014) with the pipe.

However, neither wolves' contact latency, nor their persistence or motor diversity differed significantly between the ball and pipe when these measures were analysed with mixed models. Accordingly, it is unlikely that a neophobic response affected wolves' persistence and motor diversity. This lack of neophobic response may either be due to the objects themselves not being “intimidating” enough, or due to our subjects' experience with several novel objects over their lives. It is possible that like in the study by Moretti et al. (2015), contact latency was a measure of interest in novel objects rather than neophobia. While counterbalancing the order in which the two objects were presented would have allowed better control over novelty, neophobia and generalisation, we had to ensure that all subjects interacted with the ball first to keep this study comparable to a parallel one being run on free-ranging dogs (where testing an individual repeatedly with a gap of two or more weeks was impossible).

Our first, bottom-up, descriptive, multivariate approach categorized wolves and dogs according to behavioural measures (contact latency, approach posture, manipulation likelihood, motor diversity and persistence). This approach allowed us to see how our subjects differed in their 
493 behaviour and how behavioural aspects may be correlated. Importantly, as "species" did not

494 factor into this analysis, clusters of dog/wolf data points were exclusively due to behavioural

495 variables. Results from this analysis helped us compare wolves and dogs directly in their

496 persistence and to decide which factors to include when modelling the other behaviour variables.

497 However, as the multivariate analysis was a purely exploratory approach, we made our

498 inferences and conclusions based on mixed models.

499 When directly comparing wolves' and dogs' persistence in the two tasks using mixed models, 500 our results confirm numerous other studies (Hiestand, 2011; Frank, 2011; Udell, 2015; Marshall-

501 Pescini et al., 2017c,a,b; Rao et al., 2017) that have found wolves to be more persistent than dogs

502 in object manipulation. We found these differences to hold even in the absence of humans during

503 testing, and importantly, with dogs and wolves that have the same level of experience with both,

504 humans and with interacting with different objects. A potential concern with using food as a

505 motivator in comparative problem-solving studies is that different species may have different

506 preferences for the same food. In our case, wolves and dogs did not differ in their preference for

507 meat and sausage (Rao et al., In press). A related concern is whether these tasks truly test

508 persistence or motivation to work for food. Persistence has been defined as "task-directed

509 motivation" (Griffin \& Guez, 2014), but it is important to note that disentangling these two

510 concepts is virtually impossible (and is not the focus of this study). Overall, our results can be

511 explained neither by dogs' (but not wolves) having been inhibited from interacting with objects

512 in their daily lives (e.g. pet dogs), nor by dogs preferring to use a social problem-solving strategy

513 in the presence of a human (i.e. by asking for help instead of solving the problem alone), nor by

514 differences in dogs' and wolves' preference for the food used to bait the objects.

515 Contrary to Siwak (2001), we found older dogs to be more interested in test objects. Dogs at the

516 WSC are kept differently from the beagle colony at the University of Toronto (WSC dogs live in

517 groups while the beagles in Toronto are housed individually) and potentially have different life

518 experiences. It is possible that at the WSC, older dogs have grown more accustomed to cognitive

519 testing and are more task focussed than younger dogs, who may be more interested in exploring

520 their environment instead.

521 We suggest that the results (wolves being more persistent than dogs) are in line with the 522 hypothesis that differences in dogs' and wolves' problem-solving performance is due to

523 adaptations to their respective feeding ecologies. Dogs have been proposed to be selected against 524 directly manipulating their environment and potentially for lower persistence (Hiestand, 2011)

525 with humans being intermediaries between dogs and their environment (Frank \& Frank, 1985).

526 Wolves, however, require high levels of persistence to survive in the wild (David Mech, 1966;

527 Mech \& Korb, 1978; Mech, Smith \& MacNulty, 2015). Further, wolves are more sensitive to

528 their environment (Hiestand, 2011); while they are more neophobic, they are also more

529 explorative than dogs (Moretti et al., 2015; Marshall-Pescini et al., 2017c). Considering animals

530 in the current study had the same experience of human provisioning and interaction during object 
531 manipulation, we suggest that differences in persistence are more likely due to dogs' and wolves'

532 adaptations to their respective ecological niche. The current results cannot reveal the extent to

533 which dogs' persistence is affected by their generalist-foraging style and by the active role being

534 played by humans in their feeding ecology (such as humans providing dogs with food (Sen

535 Majumder et al., 2016) or actively inhibiting them from interacting with objects, which may be

536 the case with pet dogs). Comparing dog populations with varying levels of experience with

537 humans (such as pet dogs and free-ranging dogs) may help to better understand whether dogs'

538 reduced persistence could be a result of humans inhibiting their interactiveness with objects.

539 In line with previous studies (Morand-Ferron et al., 2011; Benson-Amram \& Holekamp, 2012;

540 Huebner \& Fichtel, 2015; Borrego \& Gaines, 2016), we found motor diversity to be positively

541 linked to persistence in both tasks, in both dogs and wolves. Motor diversity and behavioural

542 flexibility is important during foraging. Being able to employ and switch between different

543 strategies both when hunting and when scavenging may increase success rates regardless of

544 foraging style. We found persistence and contact latency to be negatively correlated. Our results

545 are in line with predictions based on the concept of behavioural types (Sih \& Del Giudice, 2012).

546 Individuals that were faster to contact the apparatus, presumably were more interested and

547 proactive in their approach and were persistent.

548 Finally, we found that our subjects were consistent in their persistence and contact latency

549 between the two tasks. Persistence is an important aspect of animal personality (Gosling, 1998;

550 Svartberg, 2002; Range, Leitner \& Virányi, 2012; Sih \& Del Giudice, 2012; Massen et al.,

551 2013). We found dogs to be more consistent in their persistence (or lack thereof) and their

552 contact latency than wolves. A likely explanation for this could be that selection against

553 persistence (Hiestand, 2011) and direct manipulation of the environment (Moretti et al., 2015;

554 Brubaker et al., 2017) may have resulted in a more consistent reactive-type personality. Wolves,

555 having faced no such selection, may be more variable in their behaviour. Alternatively, wolves'

556 ability to better generalise and understand that the task is unsolvable may have influenced the

557 consistency in their performance. To disentangle these possibilities, it would be necessary to test

558 subjects in tasks that are similar in concept but in different test settings. Further, utilising

559 multiple tests would provide a better insight into inter-task performance consistency.

560 Our study was the first to test differences in persistence between similarly raised and experienced

561 dogs and wolves in an unsolvable task in the absence of humans. Past studies have used tasks

562 that have initially been solvable and later become unsolvable. It is possible that persistence may

563 differ between these two designs. The "unsolvable task" paradigm has been widely used with

564 dogs and wolves (Miklósi et al., 2003; Gácsi et al., 2005; Passalacqua et al., 2011; Smith \&

565 Litchfield, 2013; Marshall-Pescini et al., 2013; D’Aniello et al., 2015; Udell, 2015; Rao et al.,

566 2017). It involves repeatedly allowing a subject to find a solution to a simple foraging task, and

567 then modifying the task to make it unsolvable. Data about persistence are usually collected in the

568 unsolvable trial. This approach has certain drawbacks when studying the correlates of problem- 
569

570

571

572

573

574

575

576

577

578

579

580

581

582

583

584

585

586

587

588

589

590

591

592

593

594

595

596

597

598

599

600

601

602

603

solving success. First, it reinforces certain manipulative behaviours, potentially reducing the motor diversity that the subject would show in the unsolvable trial. Second, reinforcing taskengagement with solvable trials may potentially increase persistence in the unsolvable trial. A task that is unsolvable from the start may provide a more reliable measure of persistence. Third, as human presence affects dogs' and wolves' behaviour differently during the test, testing subjects in the presence of a human may make directly comparing wolves' and dogs' persistence difficult.

While several studies have investigated problem-solving behaviour in dogs and wolves, few have analysed consistency in problem-solving success in dogs (Svartberg \& Forkman, 2002;

Svartberg, 2005), and none have done so in wolves. By testing dogs and wolves in independent problem-solving tasks with and without the presence of a human, using tasks that offer either controlled or random reinforcement and by using a battery of various physical problem-solving tasks, future studies could improve our understanding of how the domestication process has affected the problem-solving behaviour in the two canids, and the role personality traits play in their problem-solving behaviour. Our study provides an interesting starting point in this direction.

\section{Conclusions}

We compared equally raised and kept pack-living wolves and dogs in an independent problemsolving task using an unsolvable task paradigm in the absence of humans. Wolves were more likely than dogs to engage in the presented tasks and were more persistent at attempting to extract food from the presented objects. Results from this study support the ecology-based hypothesis, suggesting that fundamental differences in dogs' and wolves' correlates of problemsolving success that have evolved due to differences in their feeding ecologies and are responsible for differences in their problem-solving performance. Further, persistence and motor diversity were positively correlated, and subjects were consistent in their persistence and approach latency across tasks, dogs more so than wolves.

Comparing dog populations that have different experiences with humans (e.g. pets and freeranging dogs) and testing subjects in identical tasks both, with and without humans present in the test setting may help further disentangle the human-reliance and ecology-based hypotheses. Using a battery of conceptually similar tests across varying test settings may provide better insight into the role of behavioural types or personality in problem-solving success.

\section{$7 \quad$ Acknowledgments}

The Wolf Science Centre was established by Zsófia Virányi, Kurt Kotrschal and Friederike Range and we thank all the helpers who made this possible hence indirectly supporting this research. We thank all animal trainers at the WSC for raising and caring for the animals: Rita 
604 Takacs, Marleen Hentrup, Christina Mayer, Marianne Heberlein, Lars Burkart and Cindy Voigt.

605 We thank Giulia Cimarelli and Ashish Sharma for the statistical advice. The authors further

606 thank many private sponsors including Royal Canin for financial support and the Game Park

607 Ernstbrunn for hosting the Wolf Science Centre.

6088 References

609 Akaike H. 1974. A new look at the statistical model identification. IEEE Transactions on $610 \quad$ Automatic Control 19:716-723. DOI: 10.1109/TAC.1974.1100705.

611 Atickem A., Bekele A., Williams SD. 2009. Competition between domestic dogs and Ethiopian

612 wolf (Canis simensis) in the Bale Mountains National Park, Ethiopia. African Journal of

613 Ecology 48:401-407. DOI: 10.1111/j.1365-2028.2009.01126.x.

614 Benson-Amram S., Holekamp KE. 2012. Innovative problem solving by wild spotted hyenas.

615

616 Proceedings of the Royal Society B: Biological Sciences 279:4087-4095. DOI:

617

618

619

620

621

622

623

624 10.1098/rspb.2012.1450.

Benson-Amram S., Weldele ML., Holekamp KE. 2013. A comparison of innovative problemsolving abilities between wild and captive spotted hyaenas, Crocuta crocuta. Animal Behaviour 85:349-356. DOI: 10.1016/j.anbehav.2012.11.003.

Biondi LM., Bó MS., Vassallo AI. 2010. Inter-individual and age differences in exploration, neophobia and problem-solving ability in a Neotropical raptor (Milvago chimango). Animal Cognition 13:701-710. DOI: 10.1007/s10071-010-0319-8.

Borrego N., Gaines M. 2016. Social carnivores outperform asocial carnivores on an innovative problem. Animal Behaviour 114:21-26. DOI: 10.1016/j.anbehav.2016.01.013.

Bouchard J., Goodyer W., Lefebvre L. 2007. Social learning and innovation are positively correlated in pigeons (Columba livia). Animal Cognition 10:259-266. DOI: 10.1007/s10071-006-0064-1.

Brubaker L., Dasgupta S., Bhattacharjee D., Bhadra A., Udell MAR. 2017. Differences in problem-solving between canid populations: Do domestication and lifetime experience

630

631

632

633 affect persistence? Animal Cognition. DOI: 10.1007/s10071-017-1093-7.

Cauchard L., Boogert NJ., Lefebvre L., Dubois F., Doligez B. 2013. Problem-solving performance is correlated with reproductive success in a wild bird population. Animal Behaviour 85:19-26. DOI: 10.1016/j.anbehav.2012.10.005.

634 Chavent M., Kuentz-Simonet V., Labenne A., Saracco J. 2014. Multivariate analysis of mixed 635 data: The PCAmixdata R package. 4:1-31.

636 Chavent M., Kuentz-Simonet V., Saracco J. 2012. Orthogonal rotation in PCAMIX. Advances in 637 Data Analysis and Classification 6:131-146. DOI: 10.1007/s11634-012-0105-3. 
638 Cole EF., Cram DL., Quinn JL. 2011. Individual variation in spontaneous problem-solving

639

640

641

642

643

644

645

646

647

648

649

650

651

652

653

654

655

656

657

658

659

660

661

662

663

664

665

666

667

668

669

670

671

672

673 performance among wild great tits. Animal Behaviour 81:491-498. DOI: 10.1016/j.anbehav.2010.11.025.

D’Aniello B., Scandurra A., Prato-Previde E., Valsecchi P. 2015. Gazing toward humans: A study on water rescue dogs using the impossible task paradigm. Behavioural Processes 110:68-73. DOI: 10.1016/j.beproc.2014.09.022.

David Mech L. 1966. Hunting Behavior of Timber Wolves in Minnesota. Journal of Mammalogy 47:347-348. DOI: $10.2307 / 1378147$.

Dufour V., Wascher C a F., Braun A., Miller R., Bugnyar T. 2012. Corvids can decide if a future exchange is worth waiting for. Biology Letters 8:201-204. DOI: 10.1098/rsbl.2011.0726.

Feng C., Wang H., Lu N., Chen T., He H., Lu Y., Tu XM. 2014. Log-transformation and its implications for data analysis. Shanghai archives of psychiatry 26:105-9. DOI: 10.3969/j.issn.1002-0829.2014.02.009.

Fleming PJS., Nolan H., Jackson SM., Ballard G-A., Bengsen A., Brown WY., Meek PD., Mifsud G., Pal SK., Sparkes J. 2017. Roles for the Canidae in food webs reviewed: Where do they fit? Food Webs 12:14-34. DOI: 10.1016/j.fooweb.2017.03.001.

Fontenot MB., Watson SL., Roberts KA., Miller RW. 2007. Effects of food preferences on token exchange and behavioural responses to inequality in tufted capuchin monkeys, Cebus apella. Animal Behaviour 74:487-496. DOI: 10.1016/j.anbehav.2007.01.015.

Frank H. 2011. Wolves, Dogs, Rearing and Reinforcement: Complex Interactions Underlying Species Differences in Training and Problem-Solving Performance. Behavior Genetics 41:830-839. DOI: 10.1007/s10519-011-9454-5.

Frank H., Frank MG. 1982. Comparison of problem-solving performance in six-week-old wolves and dogs. Animal Behaviour 30:95-98. DOI: 10.1016/S0003-3472(82)80241-8.

Frank H., Frank MG. 1985. Comparative manipulation-test performance in ten-week-old wolves (Canis lupus) and Alaskan malamutes (Canis familiaris): A Piagetian interpretation. Journal of Comparative Psychology 99:266-274. DOI: 10.1037/0735-7036.99.3.266.

Frank H., Frank MG., Hasselbach LM., Littleton DM. 1989. Motivation and insight in wolf (Canis lupus) and Alaskan malamute (Canis familiaris): Visual discrimination learning. Bulletin of the Psychonomic Society 27:455-458. DOI: 10.3758/BF03334654.

Frantz LAF., Mullin VE., Pionnier-Capitan M., Lebrasseur O., Ollivier M., Perri A., Linderholm A., Mattiangeli V., Teasdale MD., Dimopoulos EA., Tresset A., Duffraisse M., McCormick F., Bartosiewicz L., Gál E., Nyerges ÉA., Sablin M V., Bréhard S., Mashkour M., Bălăşescu A., Gillet B., Hughes S., Chassaing O., Hitte C., Vigne J-D., Dobney K., Hänni C., Bradley DG., Larson G. 2016. Genomic and archaeological evidence suggest a dual origin of domestic dogs. Science 352:1228-1231. DOI: 10.1126/science.aaf3161. 
674 Gácsi M., Gyoöri B., Virányi Z., Kubinyi E., Range F., Belényi B., Miklósi Á. 2009. Explaining

675

676

677

678

679

680

681

682

683

684

685

686

687

688

689

690

691

692

693

694

695

696

697

698

699

700

701

702

703

704

705

706

707

708
Dog Wolf Differences in Utilizing Human Pointing Gestures: Selection for Synergistic Shifts in the Development of Some Social Skills. PLoS ONE 4:e6584. DOI: 10.1371/journal.pone.0006584.

Gácsi M., Győri B., Miklósi Á., Virányi Z., Kubinyi E., Topál J., Csányi V. 2005. Speciesspecific differences and similarities in the behavior of hand-raised dog and wolf pups in social situations with humans. Developmental Psychobiology 47:111-122. DOI: $10.1002 /$ dev.20082.

Gosling SD. 1998. Personality dimensions in spotted hyenas (Crocuta crocuta). Journal of Comparative Psychology 112:107-118. DOI: 10.1037/0735-7036.112.2.107.

Graham MH. 2003. Confronting multicollinearity in ecological multiple regression. Ecology 84:2809-2815. DOI: 10.1890/02-3114.

Griffin AS., Diquelou MC. 2015. Innovative problem solving in birds: a cross-species comparison of two highly successful passerines. Animal Behaviour 100:84-94. DOI: 10.1016/j.anbehav.2014.11.012.

Griffin AS., Diquelou M., Perea M. 2014. Innovative problem solving in birds: a key role of motor diversity. Animal Behaviour 92:221-227. DOI: 10.1016/j.anbehav.2014.04.009.

Griffin AS., Guez D. 2014. Innovation and problem solving: A review of common mechanisms. Behavioural Processes 109:121-134. DOI: 10.1016/j.beproc.2014.08.027.

Grubbs FE. 1950. Sample Criteria for Testing Outlying Observations. The Annals of Mathematical Statistics 21:27-58.

Heberlein MTE., Turner DC., Range F., Virányi Z. 2016. A comparison between wolves, Canis lupus, and dogs, Canis familiaris, in showing behaviour towards humans. Animal Behaviour 122:59-66. DOI: 10.1016/j.anbehav.2016.09.023.

Hiestand L. 2011. A comparison of problem-solving and spatial orientation in the wolf (Canis lupus) and dog (Canis familiaris). Behavior Genetics 41:840-857. DOI: 10.1007/s10519011-9455-4.

Hillemann F., Bugnyar T., Kotrschal K., Wascher CAF. 2014. Waiting for better, not for more: corvids respond to quality in two delay maintenance tasks. Animal behaviour 90:1-10. DOI: 10.1016/j.anbehav.2014.01.007.

Huebner F., Fichtel C. 2015. Innovation and behavioral flexibility in wild redfronted lemurs (Eulemur rufifrons). Animal Cognition 18:777-787. DOI: 10.1007/s10071-015-0844-6.

Johnson-Ulrich L., Johnson-Ulrich Z., Holekamp K. 2018. Proactive behavior, but not inhibitory control, predicts repeated innovation by spotted hyenas tested with a multi-access box. Animal Cognition 21:379-392. DOI: 10.1007/s10071-018-1174-2. 
709 Komsta L. 2006. Processing data for outliers. R News 6(2):10-13.

710 Konno A., Romero T., Inoue-Murayama M., Saito A., Hasegawa T. 2016. Dog Breed

711

712

713

714

715

716

717

718

719

720

721

722

723

724

725

726

727

728

729

730

731

732

733

734

735

736

737

738

739

740

741

742

743

Differences in Visual Communication with Humans. PLOS ONE 11:e0164760. DOI: 10.1371/journal.pone.0164760.

Kozlovsky DY., Branch CL., Pravosudov V V. 2015. Problem-solving ability and response to novelty in mountain chickadees (Poecile gambeli) from different elevations. Behavioral Ecology and Sociobiology 69:635-643. DOI: 10.1007/s00265-015-1874-4.

Laland K., Reader S. 1999. Foraging innovation in the guppy. Animal behaviour 57:331-340. DOI: 10.1006/anbe.1998.0967.

Lefebvre L., Reader SM., Sol D. 2004. Brains, Innovations and Evolution in Birds and Primates. Brain, Behavior and Evolution 63:233-246. DOI: 10.1159/000076784.

Lo S., Andrews S. 2015. To transform or not to transform: using generalized linear mixed models to analyse reaction time data. Frontiers in Psychology 6:1-16. DOI: 10.3389/fpsyg.2015.01171.

Logan CJ. 2016. Behavioral flexibility and problem solving in an invasive bird. PeerJ 4:e1975. DOI: $10.7717 /$ peerj.1975.

Sen Majumder S., Paul M., Sau S., Bhadra A. 2016. Denning habits of free-ranging dogs reveal preference for human proximity. Scientific Reports 6:32014. DOI: 10.1038/srep32014.

Marshall-Pescini S., Besserdich I., Kratz C., Range F. 2016. Exploring Differences in Dogs' and Wolves' Preference for Risk in a Foraging Task. Frontiers in Psychology 7:1-12. DOI: 10.3389/fpsyg.2016.01241.

Marshall-Pescini S., Cafazzo S., Virányi Z., Range F. 2017a. Integrating social ecology in explanations of wolf-dog behavioral differences. Current Opinion in Behavioral Sciences 16:80-86. DOI: 10.1016/j.cobeha.2017.05.002.

Marshall-Pescini S., Colombo E., Passalacqua C., Merola I., Prato-Previde E. 2013. Gaze alternation in dogs and toddlers in an unsolvable task: evidence of an audience effect. Animal Cognition 16:933-943. DOI: 10.1007/s10071-013-0627-x.

Marshall-Pescini S., Schwarz JFL., Kostelnik I., Virányi Z., Range F. 2017b. Importance of a species' socioecology: Wolves outperform dogs in a conspecific cooperation task.

Proceedings of the National Academy of Sciences 114:11793-11798. DOI: 10.1073/pnas. 1709027114.

Marshall-Pescini S., Valsecchi P., Petak I., Accorsi PA., Previde EP. 2008. Does training make you smarter? The effects of training on dogs' performance (Canis familiaris) in a problem solving task. Behavioural Processes 78:449-454. DOI: 10.1016/j.beproc.2008.02.022.

Marshall-Pescini S., Virányi Z., Kubinyi E., Range F. 2017c. Motivational Factors Underlying 
744

745

746

747

748

749

750

751

752

753

754

755

756

757

758

759

760

761

762

763

764

765

766

767

768

769

770

771

772

773

774

775

776

777

778

779

Problem Solving: Comparing Wolf and Dog Puppies' Explorative and Neophobic Behaviors at 5, 6, and 8 Weeks of Age. Frontiers in Psychology 8:1-11. DOI: 10.3389/fpsyg.2017.00180.

Marshall-Pescini S., Virányi Z., Range F. 2015. The Effect of Domestication on Inhibitory Control: Wolves and Dogs Compared. PLOS ONE 10:e118469. DOI: 10.1371/journal.pone.0118469.

Massen JJM., Antonides A., Arnold A-MK., Bionda T., Koski SE. 2013. A behavioral view on chimpanzee personality: Exploration tendency, persistence, boldness, and tool-orientation measured with group experiments. American Journal of Primatology 75:947-958. DOI: 10.1002/ajp.22159.

Mech LD., Korb M. 1978. An unusually long pursuit of a deer by a wolf. Journal of Mammalogy 59:860-861. DOI: 10.2307/1380155.

Mech LD., Smith DW., MacNulty DR. 2015. Wolves on the Hunt: The Behavior of Wolves Hunting Wild Prey. University of Chicago Press.

Mettke-Hofmann C., Winkler H., Leisler B. 2002. The significance of ecological factors for exploration and neophobia in parrots. Ethology 108:249-272. DOI: 10.1046/j.14390310.2002.00773.x.

Miklósi Á., Kubinyi E., Topál J., Gácsi M., Virányi Z., Csányi V. 2003. A Simple Reason for a Big Difference: Wolves Do Not Look Back at Humans, but Dogs Do. Current Biology 13:763-766. DOI: 10.1016/S0960-9822(03)00263-X.

Morand-Ferron J., Cole EF., Rawles JEC., Quinn JL. 2011. Who are the innovators? A field experiment with 2 passerine species. Behavioral Ecology 22:1241-1248. DOI: 10.1093/beheco/arr120.

Moretti L., Hentrup M., Kotrschal K., Range F. 2015. The influence of relationships on neophobia and exploration in wolves and dogs. Animal Behaviour 107:159-173. DOI: 10.1016/j.anbehav.2015.06.008.

Newsome TM., Ballard G-A., Crowther MS., Fleming PJS., Dickman CR. 2014. Dietary niche overlap of free-roaming dingoes and domestic dogs: the role of human-provided food. Journal of Mammalogy 95:392-403. DOI: 10.1644/13-MAMM-A-145.1.

Passalacqua C., Marshall-pescini S., Barnard S., Lakatos G., Valsecchi P., Prato E. 2011. Human-directed gazing behaviour in puppies and adult dogs, Canis lupus familiaris. Animal Behaviour 82:1043-1050. DOI: 10.1016/j.anbehav.2011.07.039.

Persson ME., Roth LS V., Johnsson M., Wright D., Jensen P. 2015. Human-directed social behaviour in dogs shows significant heritability. Genes, Brain and Behavior 14:337-344. DOI: $10.1111 / \mathrm{gbb} .12194$.

R Core Team. 2017. R: A Language and Environment for Statistical Computing. 
780

781

782

783

784

785

786

787

788

789

790

791

792

793

794

795

796

797

798

799

800

801

802

803

804

805

806

807

808

809

810

811

812

813

814

R Core Team. 2018. R: A Language and Environment for Statistical Computing.

Range F., Leitner K., Virányi Z. 2012. The Influence of the Relationship and Motivation on Inequity Aversion in Dogs. Social Justice Research 25:170-194. DOI: 10.1007/s11211012-0155-x.

Range F., Virányi Z. 2013. Social learning from humans or conspecifics: Differences and similarities between wolves and dogs. Frontiers in Psychology 4:1-10. DOI: 10.3389/fpsyg.2013.00868.

Range F., Virányi Z. 2014. Wolves Are Better Imitators of Conspecifics than Dogs. PLoS ONE 9:e86559. DOI: 10.1371/journal.pone.0086559.

Rao A., Marshall-Pescini S., Virányi Z., Range F. 2017. The role of domestication and experience in 'looking back' towards humans in an unsolvable task. Scientific Reports 7:46636. DOI: 10.1038/srep46636.

Réale D., Reader SM., Sol D., McDougall PT., Dingemanse NJ. 2007. Integrating animal temperament within ecology and evolution. Biological Reviews 82:291-318. DOI: 10.1111/j.1469-185X.2007.00010.x.

Revelle W. 2017. psych: Procedures for Psychological, Psychometric, and Personality Research.

Shrout PE., Fleiss JL. 1979. Intraclass correlations: uses in assessing rater reliability.1. Shrout PE, Fleiss JL: Intraclass correlations: uses in assessing rater reliability. Psychol Bull 1979, 86:420-8. Psychological bulletin 86:420-8.

Sih A., Del Giudice M. 2012. Linking behavioural syndromes and cognition: a behavioural ecology perspective. Philosophical Transactions of the Royal Society B: Biological Sciences 367:2762-2772. DOI: 10.1098/rstb.2012.0216.

Siwak CT. 2001. Effect of Age and Level of Cognitive Function on Spontaneous and Exploratory Behaviors in the Beagle Dog. Learning \& Memory 8:317-325. DOI: $10.1101 / \mathrm{lm} .41701$.

Smith BP., Litchfield CA. 2013. Looking back at "looking back": Operationalising referential gaze for dingoes in an unsolvable task. Animal Cognition 16:961-971. DOI: 10.1007/s10071-013-0629-8.

Sol D., Griffin AS., Bartomeus I. 2012. Consumer and motor innovation in the common myna: the role of motivation and emotional responses. Animal Behaviour 83:179-188. DOI: 10.1016/j.anbehav.2011.10.024.

Sol D., Griffin AS., Bartomeus I., Boyce H. 2011. Exploring or Avoiding Novel Food Resources? The Novelty Conflict in an Invasive Bird. PLoS ONE 6:e19535. DOI: 10.1371/journal.pone.0019535.

Sol D., Lefebvre L., Rodriguez-Teijeiro JD. 2005. Brain size, innovative propensity and 
815

816

817

818

819

820

821

822

823

824

825

826

827

828

829

830

831

832

833

834

835

836

837

838

839

840

841

842

843

844

845

846

847

848 migratory behaviour in temperate Palaearctic birds. Proceedings of the Royal Society B: Biological Sciences 272:1433-1441. DOI: 10.1098/rspb.2005.3099.

Stasinopoulos DM., Rigby RA. 2007. Generalized Additive Models for Location Scale and Shape (GAMLSS) in R. Journal of Statistical Software 23:507-554. DOI: 10.18637/jss.v023.i07.

Svartberg K. 2002. Shyness-boldness predicts performance in working dogs. Applied Animal Behaviour Science 79:157-174. DOI: 10.1016/S0168-1591(02)00120-X.

Svartberg K. 2005. A comparison of behaviour in test and in everyday life: Evidence of three consistent boldness-related personality traits in dogs. Applied Animal Behaviour Science 91:103-128. DOI: 10.1016/j.applanim.2004.08.030.

Svartberg K., Forkman B. 2002. Personality traits in the domestic dog (Canis familiaris). Applied Animal Behaviour Science 79:133-155. DOI: 10.1016/S0168-1591(02)00121-1.

Thornton A., Samson J. 2012. Innovative problem solving in wild meerkats. Animal Behaviour 83:1459-1468. DOI: 10.1016/j.anbehav.2012.03.018.

Udell MAR. 2015. When dogs look back: inhibition of independent problem-solving behaviour in domestic dogs ( Canis lupus familiaris ) compared with wolves ( Canis lupus ). Biology Letters 11:20150489. DOI: 10.1098/rsbl.2015.0489.

Udell MAR., Dorey NR., Wynne CDL. 2008. Wolves outperform dogs in following human social cues. Animal Behaviour 76:1767-1773. DOI: 10.1016/j.anbehav.2008.07.028.

Vanak AT., Gomper ME. 2009. Dogs Canis familiaris as carnivores: their role and function in intraguild competition. Mammal Review 39:265-283. DOI: 10.1111/j.13652907.2009.00148.x.

Virányi Z., Gácsi M., Kubinyi E., Topál J., Belényi B., Ujfalussy D., Miklósi Á. 2008. Comprehension of human pointing gestures in young human-reared wolves (Canis lupus) and dogs (Canis familiaris). Animal Cognition 11:373-387. DOI: 10.1007/s10071-0070127-y.

Virányi Z., Range F. 2011. Evaluating the logic of perspective-taking experiments. Learning \& behavior 39:306-9. DOI: 10.3758/s13420-011-0040-8.

Webster SJ., Lefebvre L. 2001. Problem solving and neophobia in a columbiform-passeriform assemblage in Barbados. Animal Behaviour 62:23-32. DOI: 10.1006/anbe.2000.1725.

Werhahn G., Virányi Z., Barrera G., Sommese A., Range F. 2016. Wolves (Canis lupus) and dogs (Canis familiaris) differ in following human gaze into distant space but respond similar to their packmates' gaze. Journal of Comparative Psychology 130:288-298. DOI: 10.1037/com0000036. 


\section{Figure 1}

\section{Commercially available Lion Feeder Ball}

*Note: Auto Gamma Correction was used for the image. This only affects the reviewing manuscript. See original source image if needed for review. 


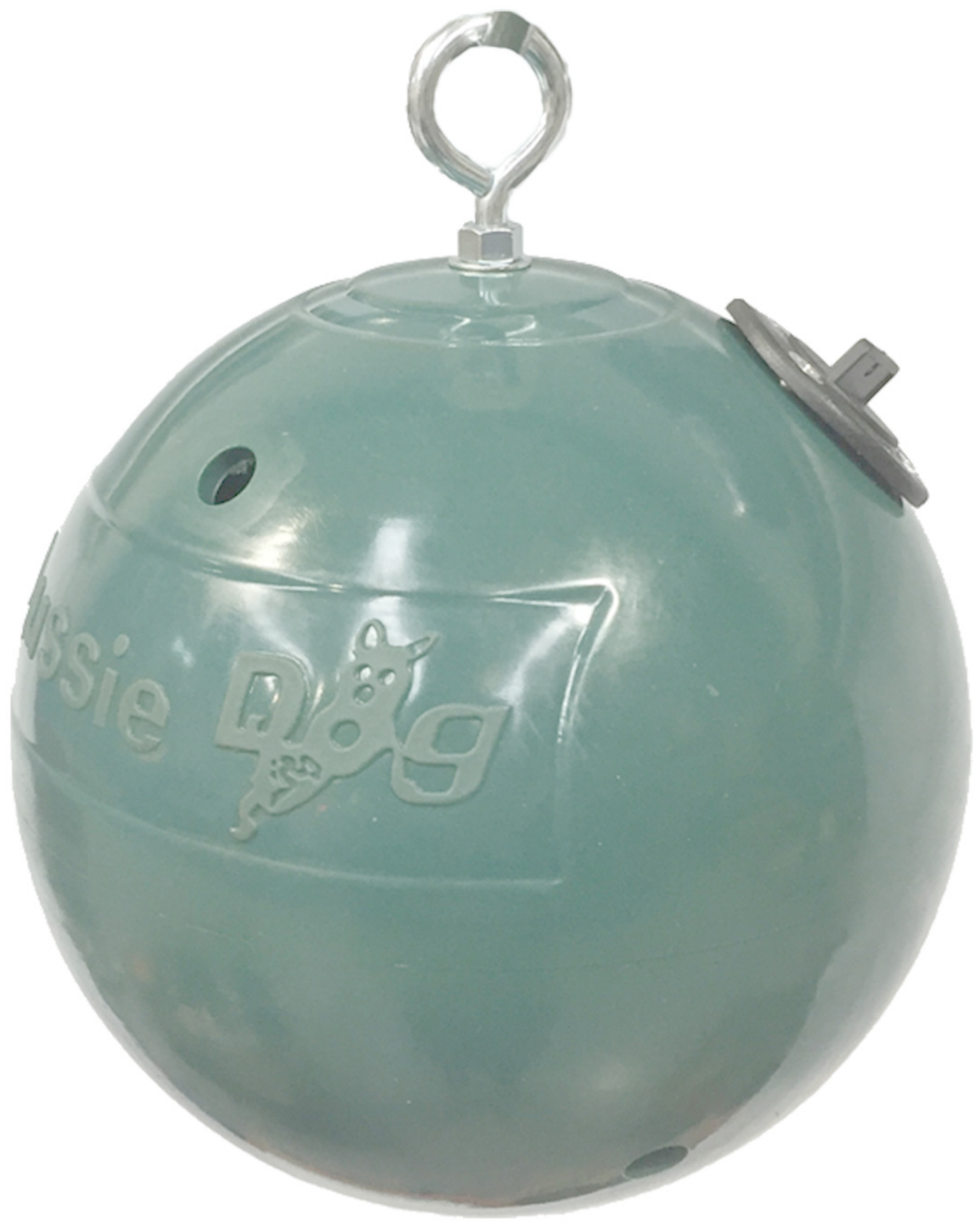




\section{Figure 2}

Modified Sewage Pipe

Photo credit: Akshay Rao

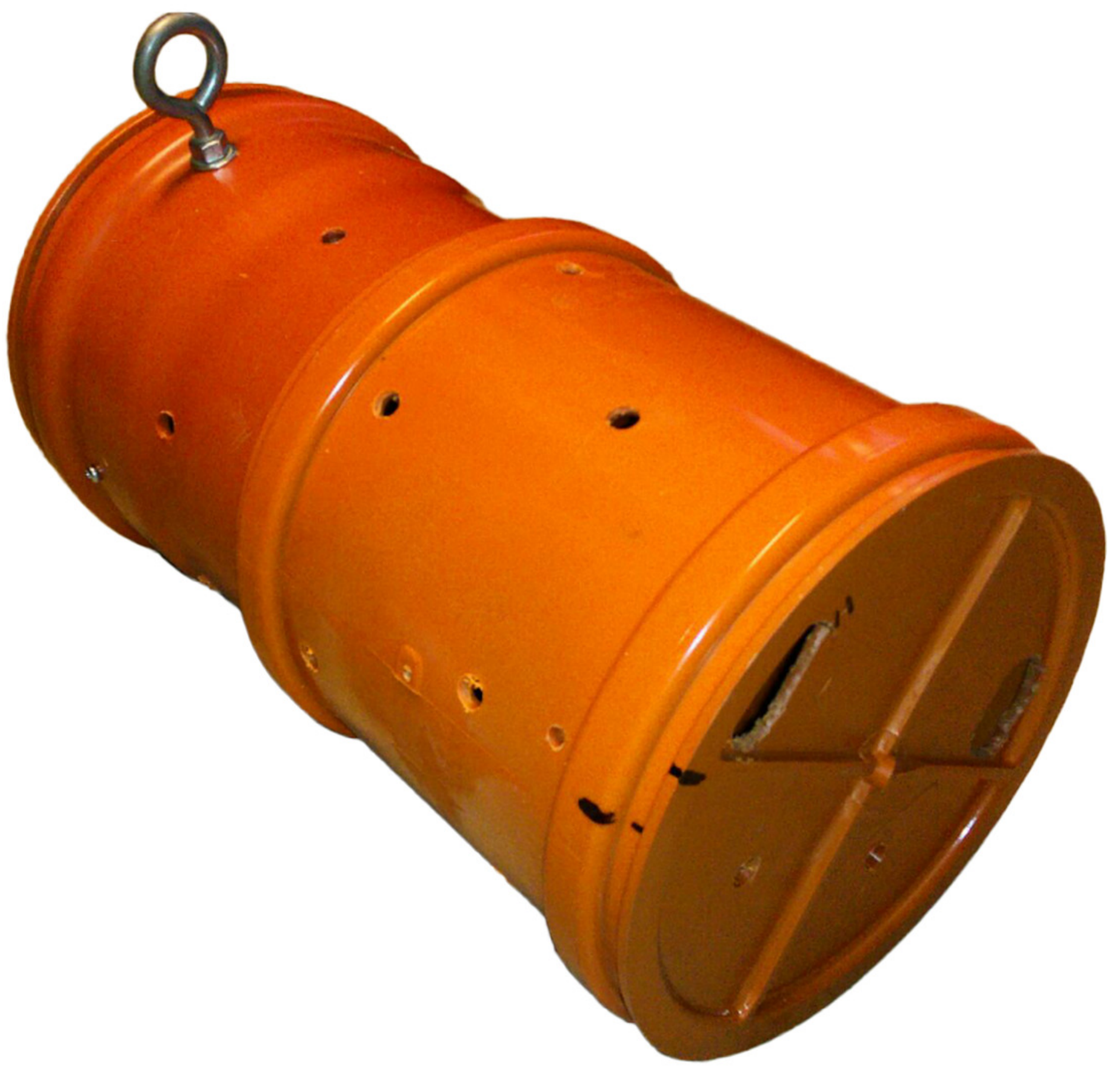


Figure 3

\section{Results for the PCA for the ball}

Panel A shows shows where each data point placed with respect to dimensions 1 and 3 (after orthogonal rotation).

Panel B shows how behavioural variables loaded on dimensions 1 and 3 (after orthogonal rotation)

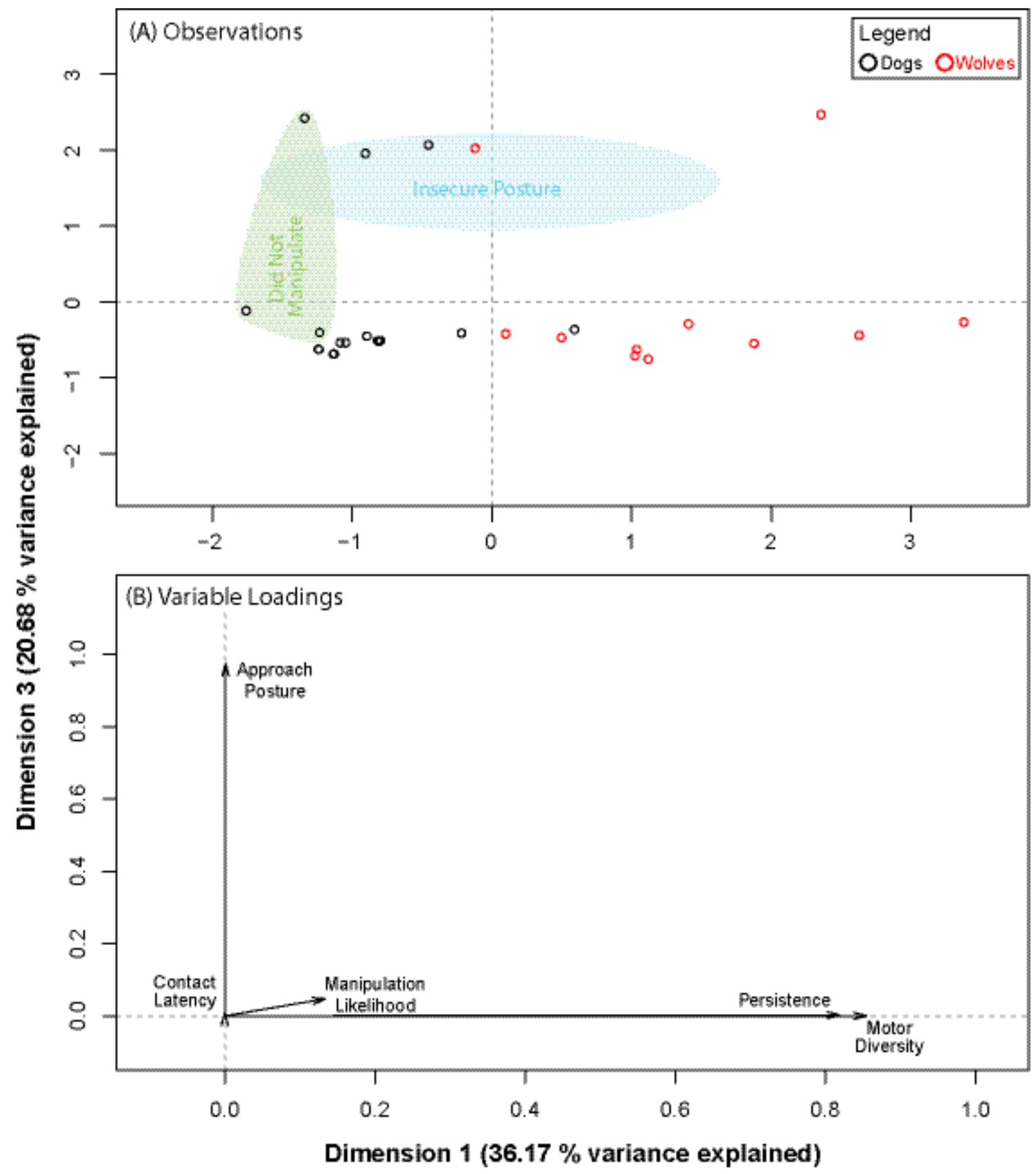


Figure 4

\section{Results for the PCA for the pipe}

Panel A shows shows where each data point placed with respect to dimensions 1 and 3 (after orthogonal rotation).

Panel B shows how behavioural variables loaded on dimensions 1 and 3 (after orthogonal rotation)

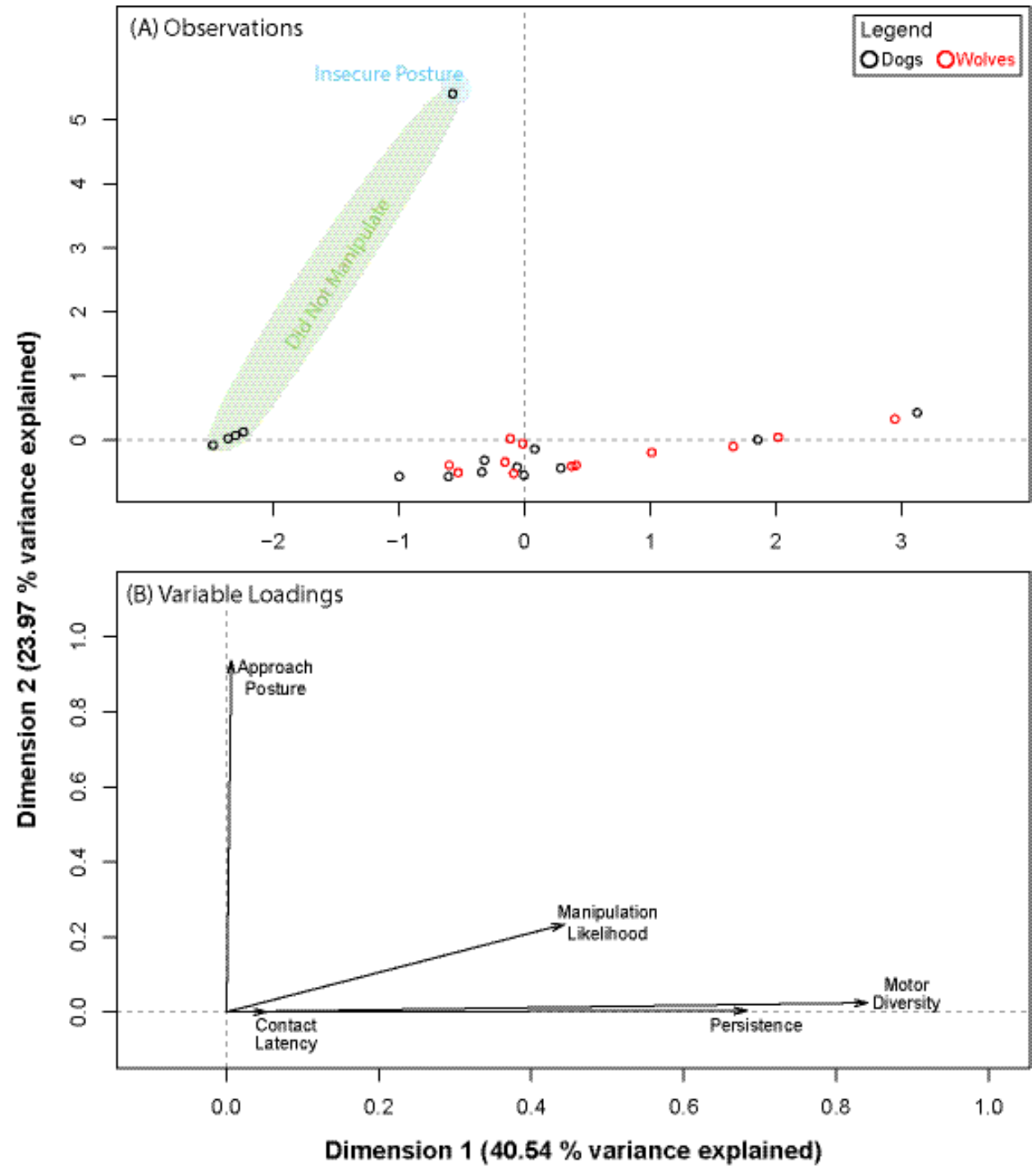




\section{Figure 5}

Differences in persistence between dogs and wolves

Panel A shows the time (in seconds) dogs and wolves spent manipulating both apparatuses combined.

Panel B shows the time (in seconds) dogs and wolves spent manipulating each object separately.

Circles indicate data points that were outside the upper quartile plus 1.5 times the interquartile distance.

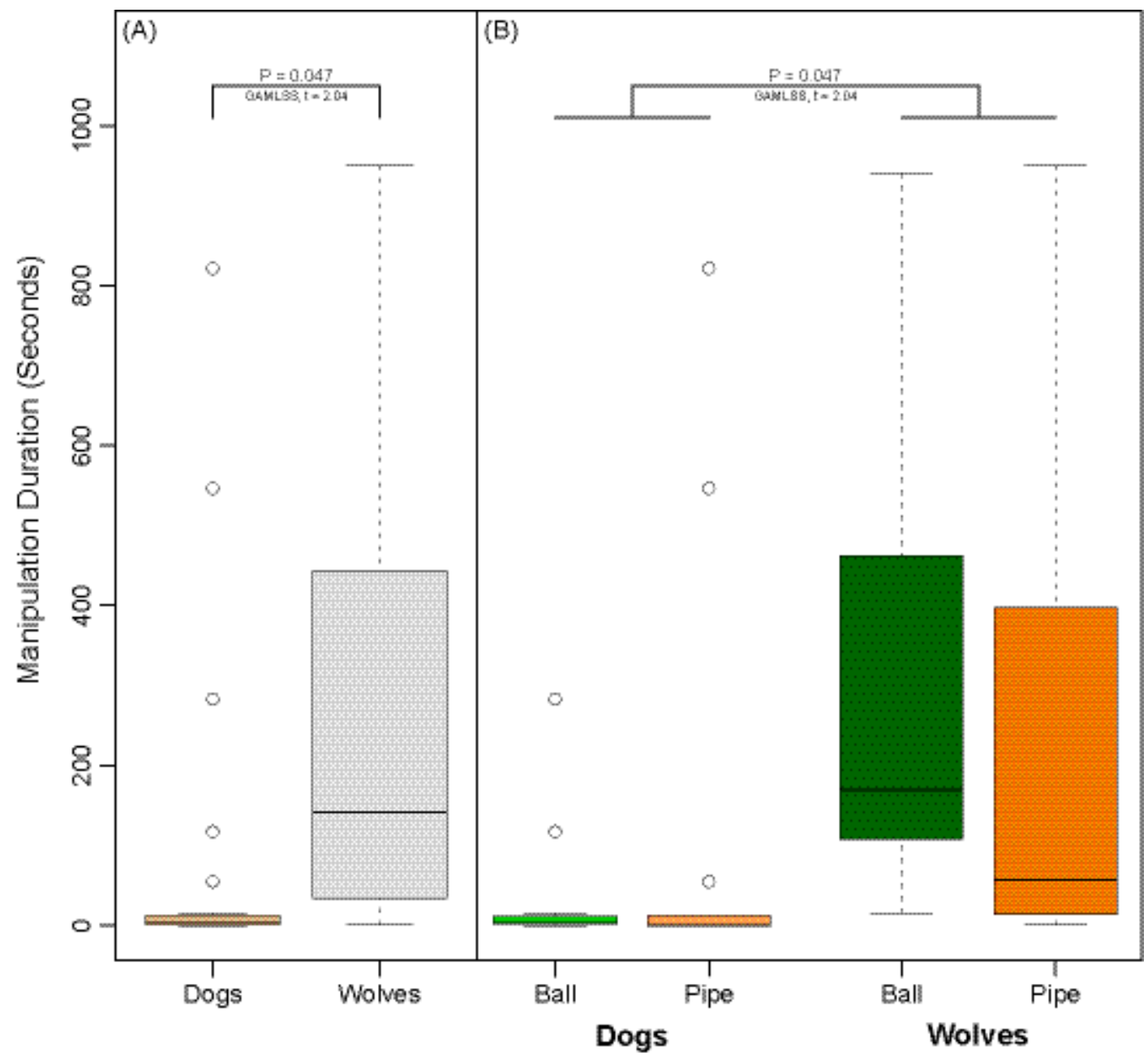




\section{Figure 6}

Every individual's persistence in both tasks, re-scaled from 0 to 1 for comparability.

Green bars indicate persistence with the ball, orange bars indicate persistence with the pipe.

Zeros indicate that the individual did not manipulate the object at all. Individuals with red names and hashed bars are wolves, individuals with black names and non-hashed bars are dogs. Individuals are arranged from left to right in descending order of consistency in persistence across tasks.

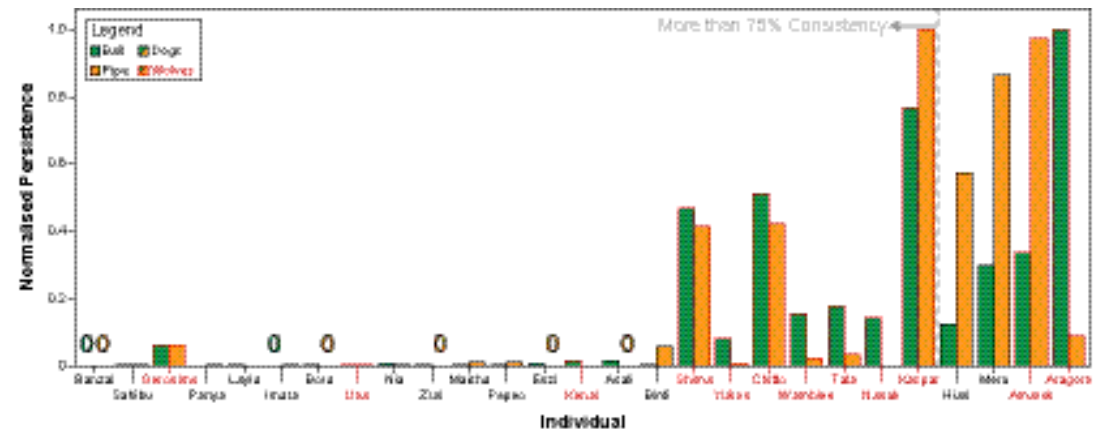




\section{Table $\mathbf{1}$ (on next page)}

Subjects 


\begin{tabular}{|c|c|c|c|c|}
\hline Subject & Species & Sex & Date of Birth & Age when tested \\
\hline Amarok & Wolf & $\mathrm{M}$ & $04 / 04 / 2012$ & 4.7 \\
\hline Aragorn & Wolf & M & $04 / 05 / 2008$ & 8.3 \\
\hline Chitto & Wolf & M & $04 / 04 / 2012$ & 4.3 \\
\hline Geronimo & Wolf & M & $02 / 05 / 2009$ & 7.3 \\
\hline Kaspar & Wolf & M & $04 / 05 / 2008$ & 8.6 \\
\hline Kenai & Wolf & M & $01 / 04 / 2010$ & 6.6 \\
\hline Nanuk & Wolf & M & $28 / 04 / 2009$ & 7.3 \\
\hline Shima & Wolf & $\mathrm{F}$ & $04 / 05 / 2008$ & 8.4 \\
\hline Tala & Wolf & $\mathrm{F}$ & $04 / 04 / 2012$ & 4.3 \\
\hline Una & Wolf & $\mathrm{F}$ & $07 / 04 / 2012$ & 4.3 \\
\hline Wamblee & Wolf & M & $18 / 04 / 2012$ & 4.5 \\
\hline Yukon & Wolf & $\mathrm{F}$ & $02 / 05 / 2009$ & 7.3 \\
\hline Asali & Dog & M & $15 / 09 / 2010$ & 5.9 \\
\hline Banzai & Dog & M & $02 / 04 / 2014$ & 2.4 \\
\hline Binti & Dog & $\mathrm{F}$ & $15 / 09 / 2010$ & 5.9 \\
\hline Bora & Dog & $\mathrm{F}$ & $02 / 08 / 2011$ & 5.0 \\
\hline Enzi & Dog & M & $02 / 04 / 2014$ & 2.3 \\
\hline Gombo & Dog & M & $21 / 03 / 2014$ & 2.4 \\
\hline Hiari & Dog & M & $21 / 03 / 2014$ & 2.4 \\
\hline Imara & Dog & $\mathrm{F}$ & $21 / 03 / 2014$ & 2.4 \\
\hline Layla & Dog & $\mathrm{F}$ & 03/08/2011 & 5.1 \\
\hline Maisha & Dog & M & $18 / 12 / 2009$ & 6.6 \\
\hline Meru & Dog & M & $01 / 10 / 2010$ & 5.8 \\
\hline $\mathrm{Nia}$ & Dog & $\mathrm{F}$ & $22 / 07 / 2011$ & 5.0 \\
\hline Nuru & Dog & M & $24 / 06 / 2011$ & 4.9 \\
\hline Panya & Dog & $\mathrm{F}$ & $02 / 04 / 2014$ & 2.4 \\
\hline Pepeo & Dog & M & $02 / 04 / 2014$ & 2.3 \\
\hline Sahibu & Dog & M & $21 / 03 / 2014$ & 2.4 \\
\hline Zuri & Dog & $\mathrm{F}$ & $24 / 06 / 2011$ & 5.1 \\
\hline
\end{tabular}


Table 2 (on next page)

Definitions of coded behaviours 


\begin{tabular}{|c|c|}
\hline Behaviour & Definition \\
\hline \multicolumn{2}{|c|}{ Approach Posture } \\
\hline Neutral & Body relaxed, tail relaxed below the plane of the back. \\
\hline Confident & Body rigid or relaxed, tail above or at the same level of the plane of the back. \\
\hline Insecure & $\begin{array}{l}\text { Tail between the legs (and wagging), and/or back (slightly) lowered, ears can be } \\
\text { rearward, and the head can be lowered, approach can be jerky and /or cautious. }\end{array}$ \\
\hline Friendly & Body relaxed, tail wagging horizontal or below the plane of the back \\
\hline \multicolumn{2}{|c|}{ Manipulation Posture } \\
\hline Insecure & $\begin{array}{l}\text { Tail between the legs, even wagging, or back lowered, ears can be rearward, } \\
\text { and the head can be lowered, body can be rigid, and movement can be jerky. }\end{array}$ \\
\hline Friendly & Tail wagging, not between the legs. \\
\hline Confident & Body rigid or relaxed, tail above or at the same level of the plane of the back. \\
\hline \multicolumn{2}{|c|}{ Behavioural States } \\
\hline Sniff & $\begin{array}{l}\text { The subject smells or attempts to smell the object with its snout less than } 10 \mathrm{~cm} \\
\text { from the object. }\end{array}$ \\
\hline Manipulating & $\begin{array}{l}\text { The subject physically manipulates the object using its paws, snout, mouth or } \\
\text { any combination of the three and shows any of the "Manipulative Behaviours". }\end{array}$ \\
\hline \multicolumn{2}{|l|}{ Markers } \\
\hline Start & The subject places a paw inside the ma \\
\hline End & $\begin{array}{l}\text { 1. The subject stops manipulating the object for } 5 \text { minutes or } \\
\text { 2. The subject has not started manipulating the object for } 5 \text { minutes after } \\
\text { making "First Contact" or } \\
\text { 3. The subject has not made "First Contact" } 5 \text { minutes after "Start". }\end{array}$ \\
\hline \multicolumn{2}{|c|}{ Manipulative Behaviours } \\
\hline Nose & The subject moves the apparatus or tries to lift it with only its nose. \\
\hline Bite & $\begin{array}{l}\text { The subject bites the object / raises the object off the ground by holding it with } \\
\text { its mouth by the chain, by the object's surface or edges, or by the screws / pulls } \\
\text { either the chain, the screws or the object's surface or edges with its mouth. }\end{array}$ \\
\hline 1 Paw & $\begin{array}{l}\text { The subject places its paw on the object without scratching it / uses one paw to } \\
\text { scratch at the top of the object while attempting to move the object towards } \\
\text { itself / away from itself / laterally. }\end{array}$ \\
\hline 1 Paw \& Bite & The subject places its paw on the object and simultaneously bites the object. \\
\hline 1 Paw \& Nose & $\begin{array}{l}\text { The subject sniffs / lifts / pushes the object with its nose or licks the object } \\
\text { while also manipulating the object with one paw. }\end{array}$ \\
\hline Paws On & $\begin{array}{l}\text { The subject places both paws on the top of the object and presses the object } \\
\text { down. }\end{array}$ \\
\hline Scratch & $\begin{array}{l}\text { The subject scratches the object's surface with both its paws by alternating them } \\
\text { (without its paws touching the ground). }\end{array}$ \\
\hline Scratch \& Bite & $\begin{array}{l}\text { The subject scratches at the object with both its paws while simultaneously } \\
\text { biting it. }\end{array}$ \\
\hline
\end{tabular}


Hold \& Bite

Dig
The subject holds and stabilises the object with both paws on the sides of it or on the top of it for the pipe, while biting it on top.

The subject uses one or both of its paws to dig at the ground in immediate proximity of the object.

\section{Other Behaviours}

Pee The subject urinates on the object or on or inside the circle.

Lick The subject licks the object.

Bark The subject vocalizes at the object.

Withdraw The subject jumps away from the object in a neutral or insecure posture after

Lay down looking at it, approaching it, sniffing it, or manipulating it. 


\section{Table $\mathbf{3}$ (on next page)}

Summary of the PCA results for the ball. 
Before Orthogonal Rotation

\begin{tabular}{|c|c|c|c|c|c|c|c|c|}
\hline \multirow{2}{*}{ Dimension } & \multirow{2}{*}{ Eigenvalue } & \multicolumn{2}{|c|}{ Variance Explained } & \multicolumn{5}{|c|}{ Variable Loadings } \\
\hline & & Individual & Cumulative & $\begin{array}{l}\text { Contact } \\
\text { Latency }\end{array}$ & Persistence & $\begin{array}{c}\text { Motor } \\
\text { Diversity }\end{array}$ & $\begin{array}{l}\text { Approach } \\
\text { Posture }\end{array}$ & $\begin{array}{c}\text { Manipulation } \\
\text { Likelihood }\end{array}$ \\
\hline 1 & 2.1059 & 42.1187 & & 0.1925 & 0.6168 & 0.7670 & 0.0353 & 0.4944 \\
\hline 2 & 1.0595 & 21.1904 & 63.3091 & 0.5968 & 0.1596 & 0.0696 & 0.0934 & 0.1401 \\
\hline 3 & 0.9985 & 19.9693 & 83.2783 & 0.0046 & 0.0454 & 0.0496 & 0.8473 & 0.0516 \\
\hline 4 & 0.6380 & 12.7605 & 96.0388 & 0.2010 & 0.1117 & 0.0156 & 0.0215 & 0.2882 \\
\hline 5 & 0.1981 & 3.9612 & 100.0000 & 0.0051 & 0.0665 & 0.0982 & 0.0025 & 0.0257 \\
\hline \multicolumn{9}{|c|}{ After Orthogonal Rotation } \\
\hline 1 & 1.8086 & 36.1719 & & 0.0001 & 0.8191 & 0.8548 & 0.0008 & 0.1337 \\
\hline 2 & 1.3214 & 26.4285 & 62.6003 & 0.7849 & 0.0003 & 0.0312 & 0.0000 & 0.5050 \\
\hline 3 & 1.0339 & 20.6780 & 83.2783 & 0.0089 & 0.0023 & 0.0002 & 0.9751 & 0.0474 \\
\hline
\end{tabular}




\section{Table 4(on next page)}

Summary of the PCA results for the pipe 
Before Orthogonal Rotation

\begin{tabular}{|c|c|c|c|c|c|c|c|c|}
\hline \multirow{2}{*}{ Dimension } & \multirow{2}{*}{ Eigenvalue } & \multicolumn{2}{|c|}{ Variance Explained } & \multicolumn{5}{|c|}{ Variable Loadings } \\
\hline & & Individual & Cumulative & $\begin{array}{l}\text { Contact } \\
\text { Latency }\end{array}$ & Persistence & $\begin{array}{c}\text { Motor } \\
\text { Diversity }\end{array}$ & $\begin{array}{l}\text { Approach } \\
\text { Posture }\end{array}$ & $\begin{array}{c}\text { Manipulation } \\
\text { Likelihood }\end{array}$ \\
\hline 1 & 2.3801 & 47.6022 & & 0.2343 & 0.6770 & 0.8871 & 0.1554 & 0.4262 \\
\hline 2 & 1.3100 & 26.1996 & 73.8018 & 0.4153 & 0.0922 & 0.0064 & 0.4906 & 0.3055 \\
\hline 3 & 0.6613 & 13.2266 & 87.0284 & 0.2499 & 0.0330 & 0.0275 & 0.2972 & 0.0537 \\
\hline 4 & 0.5132 & 10.2645 & 97.2929 & 0.0985 & 0.1593 & 0.0005 & 0.0567 & 0.1983 \\
\hline 5 & 0.1354 & 2.7071 & 100.0000 & 0.0020 & 0.0386 & 0.0785 & 0.0000 & 0.0163 \\
\hline \multicolumn{9}{|c|}{ After Orthogonal Rotation } \\
\hline 1 & 2.0270 & 40.5395 & & 0.0525 & 0.6832 & 0.8414 & 0.0062 & 0.4437 \\
\hline 2 & 1.1986 & 23.9721 & 64.5116 & 0.0002 & 0.0032 & 0.0243 & 0.9370 & 0.2339 \\
\hline 3 & 1.1258 & 22.5167 & 87.0284 & 0.8468 & 0.1158 & 0.0553 & 0.0001 & 0.1079 \\
\hline
\end{tabular}

